\title{
Estimation of degree of sea ice ridging in the Bay of Bothnia based on geolocated photon heights from ICESat-2
}

\author{
Renée Mie Fredensborg Hansen ${ }^{1,2}$, Eero Rinne ${ }^{1}$, Sinéad Louise Farrell ${ }^{3}$, and Henriette Skourup ${ }^{2}$ \\ ${ }^{1}$ Marine Research, Finnish Meteorological Institute, Erik Palménin aukio 1, 00560 Helsinki, Finland \\ ${ }^{2}$ Geodesy and Earth Observation, DTU Space, Elektrovej Building 328, 2800 Kongens Lyngby, Denmark \\ ${ }^{3}$ Geographical Sciences, University of Maryland, 2181 LeFrak hall, College Park, MD 20740, USA
}

Correspondence: Renée Mie Fredensborg Hansen (renee.fredensborg@fmi.fi)

Received: 23 October 2020 - Discussion started: 29 October 2020

Revised: 23 April 2021 - Accepted: 30 April 2021 - Published: 2 June 2021

\begin{abstract}
We present a comparison of Ice, Cloud and land Elevation Satellite-2 (ICESat-2) geolocated photon heights and operational ice charts from the Finnish Ice Service in the Bay of Bothnia in spring 2019. We show that ICESat-2 (IS2) retrievals from ice areas with different ridging characteristics, more precisely the degree of ice ridging (DIR), differ significantly. DIR is a particularly useful parameter for ice navigators, as it provides information on how difficult it is to navigate through an area based on e.g. sail heights and distribution of sea ice ridges. DIR estimates are included in ice charts of the Baltic Sea and are based primarily on in situ observations from an active icebreaker fleet. We show that DIR may potentially be estimated from IS2. We also present a comparison of IS2 measurements and Sentinel-1 synthetic aperture radar frames, discussing several individual cases of IS2 photon elevation behaviour over Baltic sea ice. We suggest that IS2 data can be of benefit to international ice services, especially if a time-critical photon height product were to be made available. Furthermore, we show that the difference between highest and mean photon elevations (elevation anomalies) of IS2 correspond to expected ridge sail heights in our study area. Our study is one of the first steps in creating sea ice applications beyond the traditional goal of freeboard and thickness retrieval for IS2.
\end{abstract}

\section{Introduction}

Rapid changes in the sea ice conditions cause challenges to ship navigation (Duncan et al., 2018). Thus, the ability to provide users with reliable and timely information on the ice conditions is time-critical and of high priority (Gegiuc et al., 2018). Some of the most important sea ice parameters for ice navigation are the ice extent, stage of development, concentration, and thickness, as well as the amount and location of ridged ice. The amount and location of ridged ice is important, since navigation through heavily ridged sea ice is difficult and potentially dangerous (e.g. Kovacs et al., 1973; Gegiuc et al., 2018; Goerlandt et al., 2017; Ronkainen et al., 2018).

The Baltic Sea extends from 54 to $66^{\circ} \mathrm{N}$ with a total area of $422000 \mathrm{~km}^{2}$ (Ronkainen et al., 2018). The seasonal ice cover usually appears in early November and persists until mid-May with the largest extent between January and March (Goerlandt et al., 2017). Wintertime shipping through the ice-covered sea into northern harbours requires timely and accurate ice information provided by the Finnish and Swedish ice services. This information is provided in the form of daily operational ice charts. Generally, the sea ice in the Baltic Sea is divided into fast and drift ice. Fast ice occurs in coastal regions and archipelagos and grows thermodynamically as it is attached to the coast where it remains stationary (Ronkainen et al., 2018). Wind and currents drive the drift ice by moving the ice floes. Divergent motion forms cracks and leads in the ice cover, and convergent motion results in formation of rafted ice and ice ridges (Gegiuc et al., 2018).

Daily ice charts of the Baltic Sea ice are prepared by Finnish Ice Service (FIS) analysts and provide a source of information on the ice conditions. The charts partition the ice cover into polygons to which ice types and other properties are assigned. Parameters assigned to each polygon 
are ice concentration, average level-ice thickness, maximum and minimum level thickness, and the degree of ice ridging (DIR). Satellite synthetic aperture radar (SAR) imagery is the main data source for ice charts, but DIR is based mostly on visual icebreaker observations. This is because DIR is designed to be a representative description of the navigational difficulties from the point of view of the navigator (Ronkainen et al., 2018).

The National Aeronautics and Space Administration (NASA) Ice, Cloud and land Elevation Satellite-2 (ICESat2) was launched on 15 September 2018 and builds upon the heritage of the Ice, Cloud and land Elevation Satellite (ICESat) mission (Neumann et al., 2019b; Abdalati et al., 2010). One of the primary mission objectives for ICESat-2 (IS2) is to estimate the thickness of sea ice and monitor any changes therein (Markus et al., 2017). The main payload of IS2 is the Advanced Topographic Laser Altimeter System (ATLAS), a photon-counting laser system operated at $532 \mathrm{~nm}$ with a pulse-repetition frequency of $10 \mathrm{kHz}$ (Kwok et al., 2019b). The ATLAS instrument employs a multi-beam configuration consisting of three pairs of beams (strong and weak beams) separated across-track by approximately $3 \mathrm{~km}$ and a pair spacing of $90 \mathrm{~m}$ (Brunt et al., 2019). The individual footprints of $\sim 17 \mathrm{~m}$ are separated by $\sim 0.7 \mathrm{~m}$ (Kwok et al., 2019a). The novel beam-pair photon-counting approach overcomes the limitations of its predecessor ICESat, as it allows for the determination of local across-track variations, e.g. sea surface height measurements in open, often narrow, leads required for sea ice freeboard and ice thickness retrievals (Markus et al., 2017). The dense surface coverage also allows for pressure ridge detection based on e.g. studies that have used the photon elevations from the Multiple Altimeter Beam Experimental Lidar (MABEL), an airborne simulator used to test the instrument theory and strategy of IS2 (Farrell et al., 2015). Furthermore, the first study using IS2 to estimate surface topography and ridges in the Arctic has recently been published (Farrell et al., 2020). IS2 is a novel instrument, and we expect that there is a vast amount of information on sea ice in the data products not currently used due to lack of methodology. Developing such novel methodology is the key driver of this study.

This paper presents a feasibility study demonstrating the use of IS2 data (granules) to estimate sea ice ridging information relevant for ice navigation. Our study is based on four IS2 passes from early 2019 in the Baltic Sea. We compare IS2's Global Geolocated Photon Data (ATL03) product to ice charts from the FIS. We have chosen the Baltic Sea as our test area, since this is, to our knowledge, the only area covered by a dense time series of ice charts where ice ridging estimates are based on frequent reports from an active icebreaker fleet (WMO, 2010). We discuss the potential of IS2 to complement satellite SAR imagery, which is widely used by ice services, and the potential benefits of a time-critical IS 2 product to international ice services.

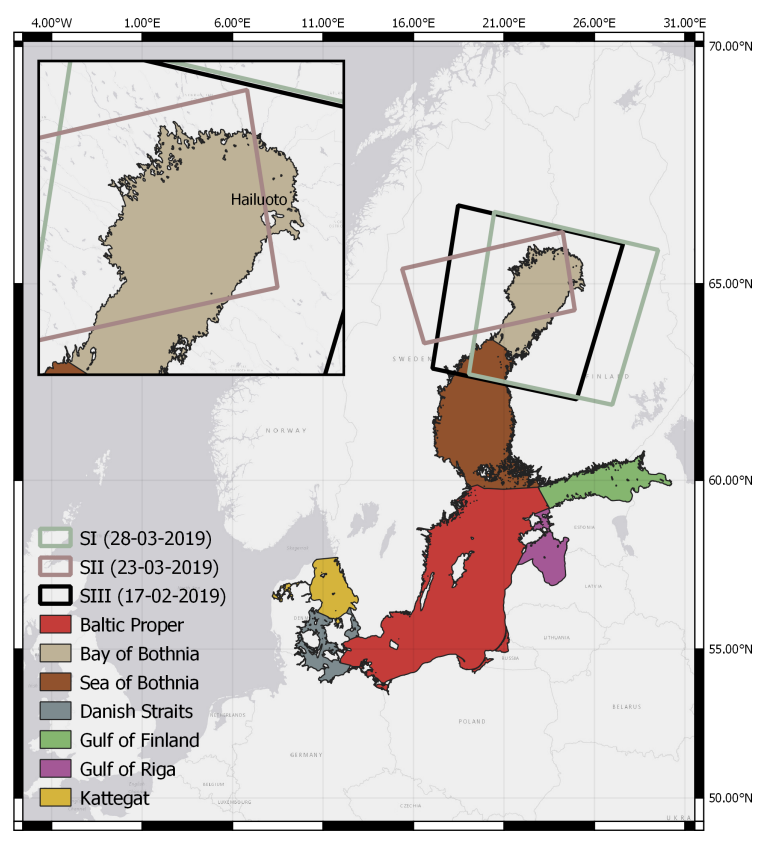

Figure 1. The Baltic Sea and its sub-basins as defined by the Baltic Marine Environment Protection Commission - Helsinki Commission (HELCOM) available at http://maps.helcom.fi/website/ mapservice/ (last access: 21 October 2020). A highlight of our study area, the Bay of Bothnia, is inset top left. The synthetic aperture radar (SAR) frames utilised for cases, described in more detail in Table 1 , are outlined as well by using the $\mathrm{kml}$ files provided in the SAR product. The Environmental Systems Research Institute (Esri) World Light Gray Base is used for background map, available at https://felix.rohrba.ch/en/download/2696/ (last access: 21 October 2020).

\section{Data and methods}

Our study area (Fig. 1) is the northernmost basin of the Baltic Sea, the Bay of Bothnia, north of the sound of Quark at $63.5^{\circ} \mathrm{N}$, during the ice season $2018 / 19$. The ice winter of $2018 / 19$ was mild with a maximum extent of the ice cover in the Baltic of $88000 \mathrm{~km}^{2}$ reached on 27 January. FIS classifies the winters as mild in the Baltic if the ice extent is below $115000 \mathrm{~km}^{2}$ (Ronkainen et al., 2018; BIM, 2019). The ship traffic was dense, where according to Baltic Icebreaking Management (BIM), 1428 vessels were assisted during the 2018/19 ice season (27 December-5 May) in the Bay of Bothnia (BIM, 2019). Even though the winter was mild, icebreakers frequently reported heavily ridged ice areas and rubble fields in February and March.

\subsection{Ice charts and degree of ice ridging}

FIS produces daily ice charts during the ice season. The ice charts are provided as both vector charts and gridded products that contain information on ice concentration, average thickness, minimum and maximum thickness, and sea surface temperature and a numeral description of deformation 
known as DIR (Gegiuc et al., 2018). DIR classifies ice into six categories (from 0 to 5 ) denoting level ice (0), rafted ice (1), slightly ridged ice (2), ridged ice (3), heavily ridged ice (4), and brash barrier (5) (Ronkainen et al., 2018). The ice charts are based on satellite SAR, visible, and infrared satellite imagery; sea ice models; and in situ measurements including observations from icebreakers and coastal observations by volunteer ice observers (Berglund and Eriksson, 2015). Weekly ice charts including DIR dating from 1980 are available in a digital format. At the time of writing they are available only on request from the FIS. However, sea ice concentration and ice thickness from the FIS charts has been publicly available via the Copernicus Marine Service since July 2018 (https://resources.marine.copernicus.eu/ ?option=com_csw\&view=details\&product_id=SEAICE BAL_SEAICE_L4_NRT_OBSERVATIONS_011_004, last access: 27 May 2021).

The quality of and uncertainty in the ice chart depends partly on the quality of the SAR imagery but also on the experience of the ice analyst, both of which can result in inconsistencies in the final ice chart. Assigning a DIR value to each ice chart polygon is a complex process that requires a profound understanding of the current ice season and ice development (Gegiuc et al., 2018). Most importantly, routine reports from the Finnish and Swedish icebreaker fleets are used to estimate ridging. It should be noted that assigning one numeral to a large area of sea ice is necessarily a simplification - in reality the ice in the area is always a mixture of several ice types. We emphasise that the FIS ice chart carries more information than just that from satellite SAR imagery. Because of the high number of vessels in the Baltic at all times, FIS ice charts utilise significantly more in situ knowledge than Arctic ice charts. During the ice winter 2018/19, FIS received 1628 ice reports from icebreakers (BIM, 2019). For this reason they are used here as the reference data set.

DIR and satellite data have been compared to each other by Gegiuc et al. (2018). To build an automatic method to derive DIR from SAR imagery, they applied a random forest algorithm to dual-polarised (HH-HV) RADARSAT-2 SAR, where $\mathrm{H}$ denotes horizontal and $\mathrm{V}$ denotes vertical polarisation, and used the FIS ice charts as reference data. The results were promising when a significant amount of ridging had occurred, allowing for the ridging to strongly contribute to the texture of the SAR images. To the best of our knowledge, this is the only study that utilises satellite measurements to estimate DIR to supplement ice charting. Analogously, we investigate the possibility of estimating DIR from IS2.

\subsection{The Ice, Cloud and land Elevation Satellite-2 (ICESat-2)}

IS2's main payload, the laser altimeter ATLAS employs a multi-beam configuration consisting of six beams (three beam pairs each with a strong and a weak beam). The strong beams are $\sim 4$ times the pulse energy of the weak ones
(Kwok et al., 2019a). Left (of individual beam pairs' imaginary centrelines) beams are denoted by GTL and right beams by GTR. The number of specific beam pair (dependent on the orientation of the spacecraft) ranges from one to three. The IS2 reference ground track (RGT) is an imaginary centreline of the ground track pattern of the multi-beam configuration, and it takes $91 \mathrm{~d}$ to sample all 1387 unique RGTs, fulfilling one full cycle (Brunt et al., 2019). One orbit track is divided into 14 granules (latitude-dependent regions) to limit data size to a maximum of $6 \mathrm{~GB}$, such that the Bay of Bothnia appears in granule region 03 on ascending tracks $\left(59.5-80^{\circ} \mathrm{N}\right)$ and granule region 05 on descending ones (80$59.5^{\circ} \mathrm{N}$ ) (Neumann et al., 2020).

\subsubsection{Global Geolocated Photon Data (ATL03) product}

In our study, we use the Global Geolocated Photons Level2A data product (ATL03) from IS2 (Neumann et al., 2019a). ATL03 is produced by combining the laser pointing vectors, the position of the IS2 observatory, and the individual photon times of flight from ATL02 (Science Unit Converted Telemetry Level 1B Data Product) (Neumann et al., 2019b). ATL03 includes the longitude (lon_ph), latitude (lat_ph) and World Geodetic System 1984 (WGS 84) ellipsoidal heights of the photons $\left(h \_p h\right)$ alongside a coarse discrimination of what is likely signal and what are background events (signal_conf_photon); a surface classification to identify land, ocean, land ice, sea ice, and inland water (with surfaces overlapping by $20 \mathrm{~km}$ ); geophysical corrections to be applied (Earth Gravitational Model 2008 (EGM2008) geoid (geoid), Mog2D dynamic atmosphere correction as calculated by Archiving, Validation and Interpretation of Satellite Oceanographic data (AVISO) (dac), and ocean tide given by the GOT4.8 model (ocean_tide)); and other parameters useful for higher-level products (Neumann et al., 2019b).

The coarse discrimination of signal and background photons is based on generated along-track histograms. The identification of signal photon events is based on the location of regions where the photon event rate is significantly larger than the background photon event rate. All photons in a given bin are classified as either signal or background events. The planned data latency of ATL03 is $21 \mathrm{~d}$, where latency is defined as the approximate time from data acquisition to data products reaching the end users in a suitable format (Brown et al., 2016).

We found four overpasses with clear-sky conditions in our study region where IS2 measured ice areas that were marked as ridged (DIR2-DIR4) in the FIS ice charts, i.e. on 1 February, 17 February, 23 March, and 27 March 2019. Data from these dates are used in our study. The different DIR areas measured by IS2 as well as satellite ground tracks are shown in Sect. 3.1. IS2 sampled DIR2 on 1 and 17 February, DIR3 on 23 and 27 March, and DIR4 solely on 27 March. 
Table 1. Sentinel-1 (S1) frames utilised in this study with ID number for comparison with cases and dates for acquisition for both S1 and ICESat-2 (IS2); see Table 3. Dates are provided in the UTC time frame.

\begin{tabular}{lllll}
\hline ID & Platform & Date (S1) & Date (IS2) & $\Delta t$ \\
\hline SI & S1B & 28 March 04:57:15 & 27 March 18:22:53 & 10h 35 min \\
SII & S1B & 23 March 16:05:32 & 23 March 18:31:14 & 2 h 26 min \\
SIII & S1B & 17 February 15:49:12 & 17 February 07:44:19 & 8 h 5 min \\
\hline
\end{tabular}

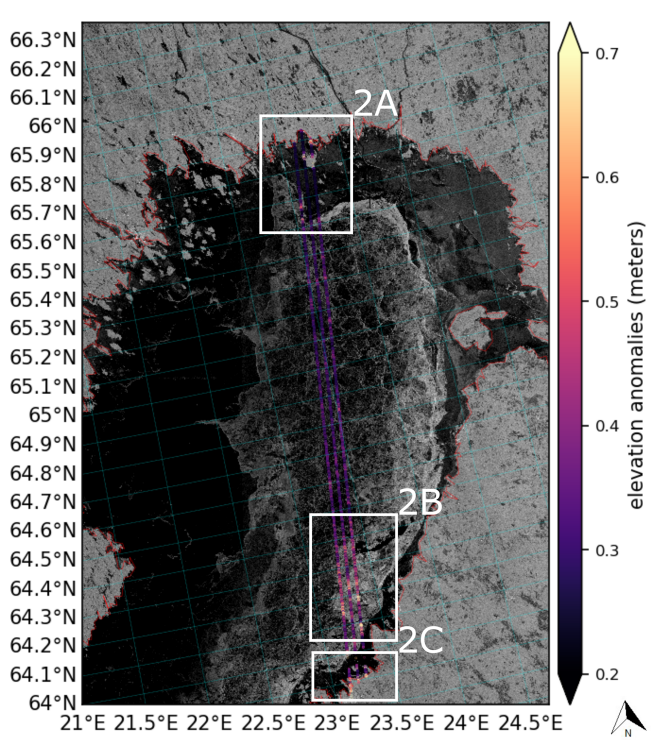

Figure 2. Elevation anomalies calculated using IS2 photons acquired 27 March 2019, overlaying S1 C-band (HV polarisation) SAR image acquired $\sim 0.45 \mathrm{~d}(10 \mathrm{~h} 35 \mathrm{~min})$ after IS2. Note the higher elevation anomalies acquired over more ridged ice (strong backscatter in white in SAR image). Areas mentioned in text are denoted 2A-2C.

\subsection{Sentinel-1 (S1) C-band synthetic aperture radar (SAR) imagery}

ESA launched the first satellite in the Copernicus Sentinel programme (Sentinel-1A; S1A) in 2014, later joined by its twin satellite Sentinel-1B (S1B) in 2016. Flying in a twinconstellation tandem phase, they provide $6 \mathrm{~d}$ coverage of the Earth (individually $12 \mathrm{~d}$ repeat orbits), where they capture the surface using SAR imagery at the $\mathrm{C}$ band $(5.4 \mathrm{GHz})$ (Kwok et al., 2019b). For this study, we utilise the Extra Wide (EW) swath mode at a high resolution (HR) of $50 \times 50 \mathrm{~m}$ and swath width of $410 \mathrm{~km}$. The HR has a pixel spacing of $25 \times 25 \mathrm{~m}$ in EW mode (Stasolla and Neyt, 2018). The S1A and S1B data were processed by ESA and archived at the Alaska Satellite Facility. In total, three SAR frames have been retrieved to discuss selected cases (Sect. 3.2); see overview provided in Table 3. All retrieved SAR frames (SI-SIII) were acquired in HV-HH polarisation.

\subsection{Estimation of degree of ice ridging using ICESat-2 (IS2) photons}

Our hypothesis is that the areas of heavier ridging (high DIR) should be distinguishable within the ATL03 photon elevations since the heavier the ridging, the higher the ridge sail heights, and thus a larger number of the measured elevations should be higher than the elevation of level ice, when compared to areas with less ridging. This assumption is only based on the amplitude of the ridging in the areas and not on spatial parameters, e.g. ridge density. Thus, we investigate the distributions of the photon elevations over a segment of $N=150$ photons. This corresponds to segments of approximately $17 \mathrm{~m}$ in length (based on measurements of one strong beam (GT3L) from 17 February 2019, but exact segment length varies with the number of geolocated photons reflected from the surface). We filter the ATL03 photons by selecting photons of only high signal confidence and apply the geophysical corrections. The geophysical corrections are part of the pre-processing filtering. We also discarded all measurements that deviated from the geoid elevation by more than $3 \mathrm{~m}$. On average, with the described preprocessing steps above (high signal confidence, $\pm 3 \mathrm{~m}$ from geoid elevation, and applying a bounding box covering only the Bay of Bothnia), $19.86 \%$ (ranging from $8.32 \%-38.65 \%$ ) of the ATL03 photons were discarded. The largest number of photons were discarded on 1 February and 23 March 2019, where between $14.81 \%-38.65 \%$ were removed in the preprocessing steps. Fewer were discarded on 17 February and 27 March, ranging between $8.32 \%-17.44 \%$. We emphasise that for these four dates, most of the photons discarded were due to the $\pm 3 \mathrm{~m}$ requirement. Only a few beams (three strong beams on 23 March 2019) had photons discarded by the highsignal-confidence flag $(0.01 \%-0.02 \%, 32-54$ photons $)$. We further emphasise that before actual pre-processing, all available tracks in the period of interest (winter 2019) were qualitatively assessed and only tracks with a clear signal from the (sea ice) surface were chosen. Several of the tracks were completely disturbed by clouds. If these tracks were to be included in the analysis, most of the cloud-contaminated photons would most likely be discarded by selecting only those assigned as high confidence, because the onboard processor would already have identified the photons to be of low or medium signal confidence. This will be discussed in further detail in Sect. 3.3.1. We reiterate that the signal confidence 
flag does not discriminate between reflections from the sea ice/ocean surface and clear reflections originating from e.g. the top of clouds. It is merely a flag providing confidence of whether the onboard processor has identified the photon as an actual signal photon and not a background photon coming from e.g. the sun. To eliminate sea level changes and differences between actual sea surface height and the geoid, we subtract the mean elevation of each segment from all of the individual photon elevations within that segment.

We then examine the distribution of the highest elevation taken relative to the mean elevation of each segment. This relative elevation or elevation anomaly, $h_{\mathrm{a}}$, of the highest elevation within a segment of $i=150$ photons subtracted from the mean elevation of this segment is defined as

$h_{\mathrm{a}}=\left[h_{\max }-h_{\text {mean }}\right]_{150}^{i=1}$,

where $h_{\max }$ is the highest elevation within a given segment and $h_{\text {mean }}$ is the average elevation of the same segment. Thus, we find one $h_{\mathrm{a}}$ value for each IS2 segment. To investigate whether the elevation anomalies correspond with sea ice features visible in SAR frames, we compare the elevation anomalies from 27 March 2019 with C-band SAR imagery from $\mathrm{S} 1$; see Fig. 2 (acquired $\sim 11 \mathrm{~h}$ after IS2 acquisition; see Table 1).

From Fig. 2, it is clear that small elevation anomalies $(\sim 0.3 \mathrm{~m}$ or less) appear over fast-ice regions (northernmost part of the track, dark purple, region 2A) and that some higher elevation anomalies, likely caused by land contamination, appear in these data (southernmost part of the track, bright colours, region $2 \mathrm{~B}$ ). We note that no land mask has been applied to remove photons covering land. In the drift ice region far from the coast, differences in elevation anomalies are evident. In the southern part of the track, an area associated with a higher degree of deformed ice (visible as high backscatter in SAR data, bright colours) yields higher IS2 elevation anomalies (green-blue-purple colours) than was found over fast ice. Furthermore, edges of the drifting ice crushing against fast ice can also be seen in the elevation anomalies (northern part of the track, bright colours, region $2 \mathrm{C}$ ), showing the increased deformation likely to occur where the drifting sea ice is pushed against the stationary fast ice.

When we examine the distributions of the elevation anomalies, we find that the distributions of the relative elevations differ with respect to the different FIS DIR zones (Fig. 3a) but with significant overlap. However, if we select only the highest $20 \%, 10 \%, 5 \%$, or $1 \%$ of the relative elevations (Fig. 3b-e) falling within a DIR zone, the separation between the DIR zones increases significantly. Focusing only on the high end of the distributions $(1 \%-10 \%$ of the highest relative elevations) corresponds to investigating segments where there is significant height difference between the highest measurement and the mean elevation - that is, focusing only on the highest ridge sails within a segment. This suggests that DIR in our study area can be estimated from
Table 2. Estimated mode, mean absolute deviation (MAD), and intervals (thresholds) from 95 th percentile (5\% highest values) of the elevation anomalies, $h_{\mathrm{a}}$, for each DIR zone. The thresholds are given by the modal value \pm MAD. Adjusted intervals are simply to exclude the gap between DIR3 and DIR4. Values in parentheses show the 98th percentile of elevations subtracting the mean rather than the elevation anomaly $h_{\mathrm{a}}$, which could potentially be useful for excluding possible noise measurements. The 98th-percentile approach is discussed further in Sect. 3.3.

\begin{tabular}{lrrrr}
\hline $\begin{array}{l}\text { Ridging } \\
\text { zone }\end{array}$ & $\begin{array}{r}\text { Mode } \\
(\mathrm{m})\end{array}$ & $\begin{array}{r}\text { MAD } \\
(\mathrm{m})\end{array}$ & $\begin{array}{r}\text { Intervals (modal } \\
\pm \text { MAD) }(\mathrm{m})\end{array}$ & $\begin{array}{r}\text { Adjusted } \\
\text { intervals }(\mathrm{m})\end{array}$ \\
\hline DIR2 & 0.43 & 0.05 & $\begin{array}{r}0.39-0.48 \\
(0.28-0.37)\end{array}$ & $\begin{array}{r}0.38-0.48 \\
(0.28-0.37)\end{array}$ \\
\hline DIR3 & 0.54 & 0.06 & $\begin{array}{r}0.48-0.60 \\
(0.05)\end{array}$ & $\begin{array}{r}0.48-0.60 \\
(0.37-0.47)\end{array}$ \\
\hline DIR4 & 0.69 & 0.06 & $0.63-0.75$ & $0.60-0.75$ \\
& $(0.55)$ & $(0.05)$ & $(0.49-0.59)$ & $(0.49-0.59)$ \\
\hline
\end{tabular}

ATL03 simply by looking at the highest percentile of relative elevations.

We built a simple threshold-based classification scheme to extract DIR values from IS2, based on the distributions in Fig. 3. While there is already a clear separation at $90 \%$, large overlaps remain between the distributions for DIR2 and DIR3 (Fig. 3c). This precludes the use of a simple threshold-based classification to distinguish between the two DIR zones in this case. For the 95th percentile (i.e. the $5 \%$ highest elevations) the overlap between the DIR zones is reduced (Fig. 3d). Since the distributions are skewed towards higher elevations, we use the mean absolute deviation (MAD) to estimate the thresholds instead of the classic standard deviation (SD). MAD is simply the median of the absolute deviations from the median and acts as a more robust dispersion measure in the presence of outliers, whereas SD is especially affected by outliers (Leys et al., 2013). Estimations of mode, MAD, and the given intervals for each DIR zone (modal \pm MAD) using the 95th-percentile data are provided in Table 2. To exclude a gap between DIR3 and DIR4, a small adjustment (of $\leq 0.03 \mathrm{~m}$ ), based on manual interpretation, is applied to the intervals. We note that the intervals are based on the $5 \%$ highest elevation anomalies (using 95thpercentile data), as we assume the highest elevation anomalies will include information on the ridges. Were one to use all of the elevation anomalies, it would also include elevation anomalies from the level ice (as seen by the overlapping distributions in Fig. 3a). 

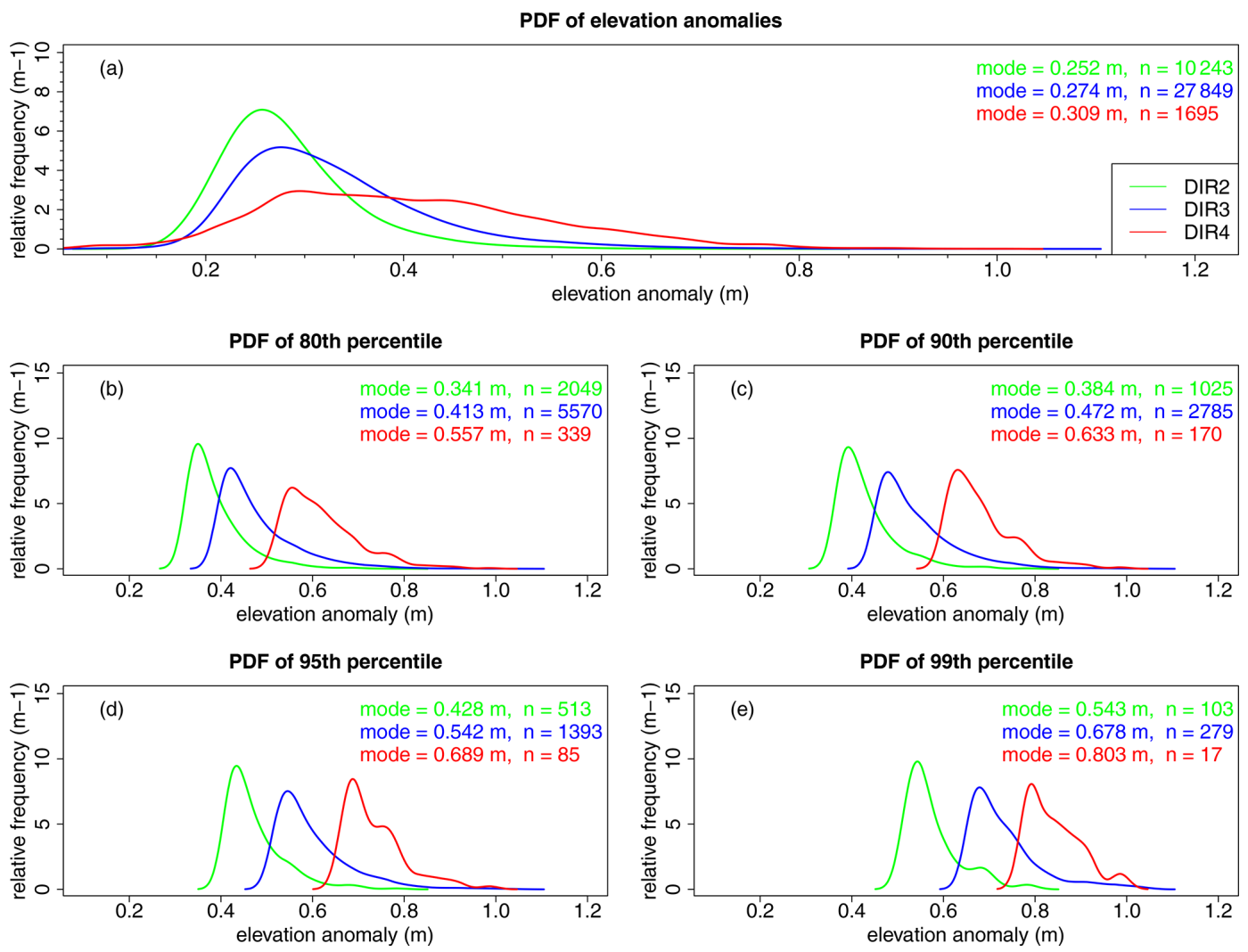

Figure 3. Distributions of elevation anomaly $\left(h_{\mathrm{a}}\right)$ to estimate different degree of ice ridging (DIR) zones. DIR2, DIR3, and DIR4 are shown in green, blue, and red, respectively. (a) Distributions of $h_{\mathrm{a}}$ of all segments; (b) distributions of 80th percentile values of $N=150$-photon segments (the $20 \%$ highest values); (c) the 90th-percentile values (10\% highest values); (d) 95th-percentile values (5\% highest values); (e) 99th-percentile values (1\% highest values). The modal value and number of included observations $(n)$ for each distribution are provided in the graphs.

\section{Results and discussion}

\subsection{Degree of ice ridging in the Bay of Bothnia}

By using the simple threshold-based classification method, we classify IS2's geolocated photon heights into the different DIR categories and present the results in Fig. 4, together with the DIR zones provided by the FIS ice charts. As expected, IS2 photons classified as DIR2 (slightly ridged ice) occur in all FIS DIR zones simply because there are areas with smoother surfaces, i.e. level-ice floes between ridges, in all zones. Similarly, IS2-derived values of DIR3 and DIR4 will also be present in a DIR2 zone since even if the area has comparably little deformation, there may be individual ridges present. In other words, IS2 is able to distinguish features at much smaller scales than the resolution of an ice chart or indeed what is practical for tactical navigation.

The general behaviour of the distributions of IS2 DIR estimates follows the DIR zones from the ice charts. However, IS2 data carry much more information than just the overall DIR for the zone. As mentioned before, the ice chart DIR is a simplification, and in reality large areas that have been as- signed to one single DIR are a mixture of several ice types and stages of deformation. If ridge features are sparsely distributed and the area has a relatively large amount of open water, the zone will be assigned DIR2 by the FIS. For heavily deformed ice, Fig. 4d shows a cluster of IS2 classified as DIR4 near and in the DIR4 zone of the ice chart (Region B). The presence of IS2 DIR3 is also larger in the southern part of the track (near the border of DIR4) compared to the northern part in line with the ice charts. There is a large number of IS2 DIR2 values in the DIR3 area, suggesting that this part of DIR3 has less ridging. However, this is only based on an amplitude parameter representing the ridge sail heights and one track; the surrounding behaviour and conditions of the ice are not known, and it is expected that DIR2 will be present in both the DIR3 and the DIR4 zones.

In general, Fig. $4 \mathrm{c}$ seems to have more IS2 DIR4 values (even compared with Fig. 4d) that actually encounter a region classified as DIR4. Since this track is close to the coast, more deformation is expected to occur due to the ice drift pushing ice floes towards the coast and fast ice. What is also clear from all four dates (Fig. 4a-d) is that when IS2 travels over fast-ice regions, the DIR values are almost non-existent 

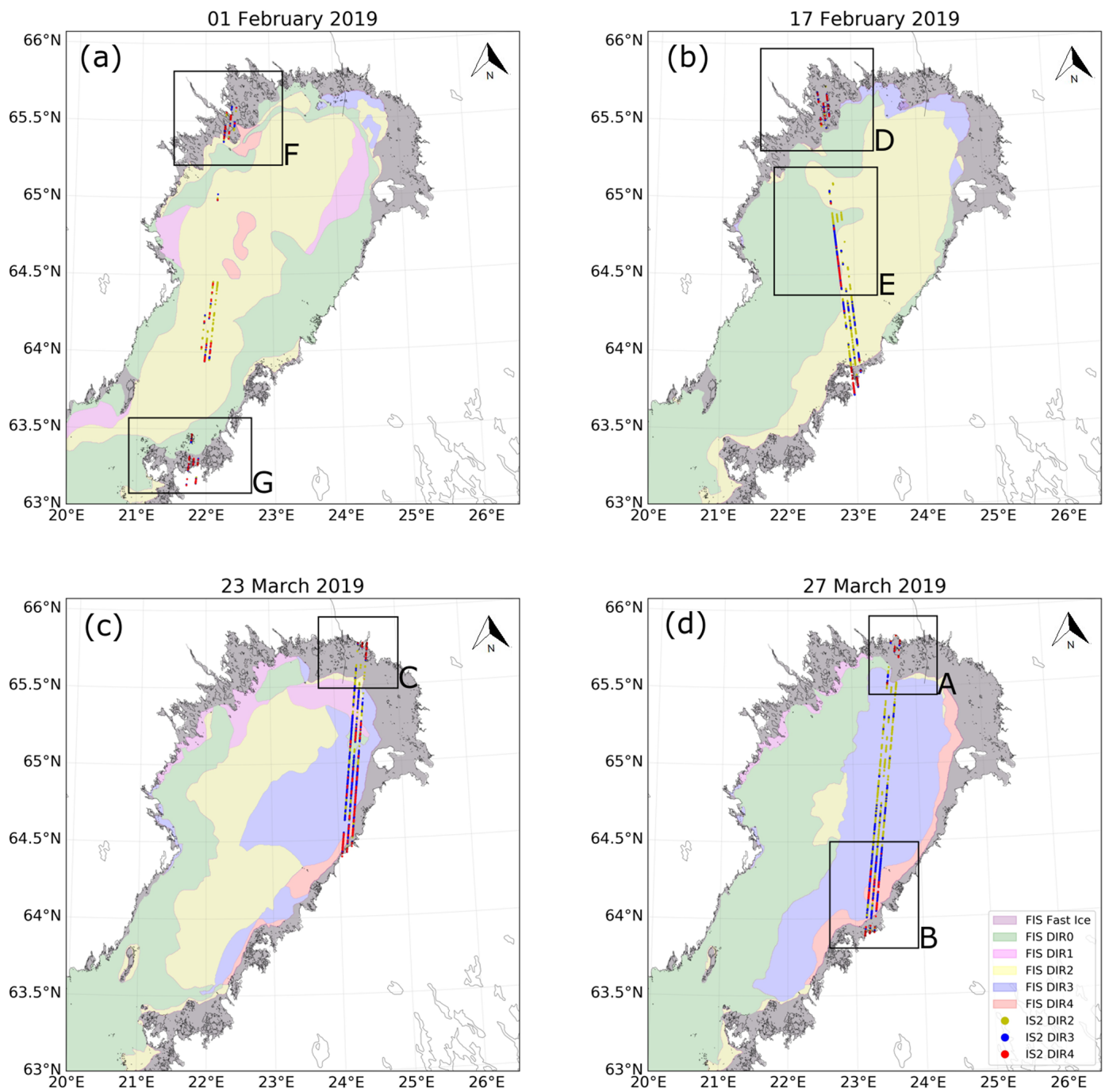

Figure 4. Categorised DIR data over four available dates (strong beams): (a) 1 February, (b) 17 February, (c) 23 March, and (d) 27 March 2019. Contours show DIR polygons derived from Finnish Ice Service (FIS) ice charts. IS2 photon heights have only been classified for DIR2-DIR4, from which several photon heights could be extracted. Darker areas close to the coast denote fast ice. A-G denote different areas of interest mentioned in the text.

except for a few segments close to the coast or over small islands (e.g. regions A-D, F, and G), caused by land contamination. We attribute this to regions of fast ice primarily consisting of smooth level ice represented by small differences in the elevation anomalies and the fact that level ice overall carries more snow than drift ice, which could smooth the surface even further. For the regions A-D (Fig. 4c, d) and G (Fig. 4a) it is clear that there are few DIR values over fast ice and the ones that are detected are actually located over land. Region F (Fig. 4a) behaves unexpectedly; there are significant DIR values which cannot be explained by land contamination; i.e. they are not close to the coast. Region F has some coastal values but mostly DIR2 values. This can be partly explained by the fact that it is very close to a DIR2 polygon or that the ice within this zone is slightly deformed. Regions D and E (Fig. 4b) show higher IS2 DIR values (DIR3 and DIR4) in places that are not within or near a similar FIS DIR zone. This could be caused by several things; it may be caused by photons within a segment, which are not surface photons but are instead caused by background photons from the sun. While the histogram approach mentioned in Sect. 2.2.1 keeps photons flagged as surface signal, the bins categorised as surface can still include some background photon events (if the background rate threshold is set too low), thus introducing a spread about the true surface. Some of the photons may also be caused by (lowlying) cloud cover interfering with the photons, which has not been entirely filtered out in the high-signal-confidence pre-processing step. Furthermore, these could be proper measurements of the ice surface affected by ocean waves pene- 

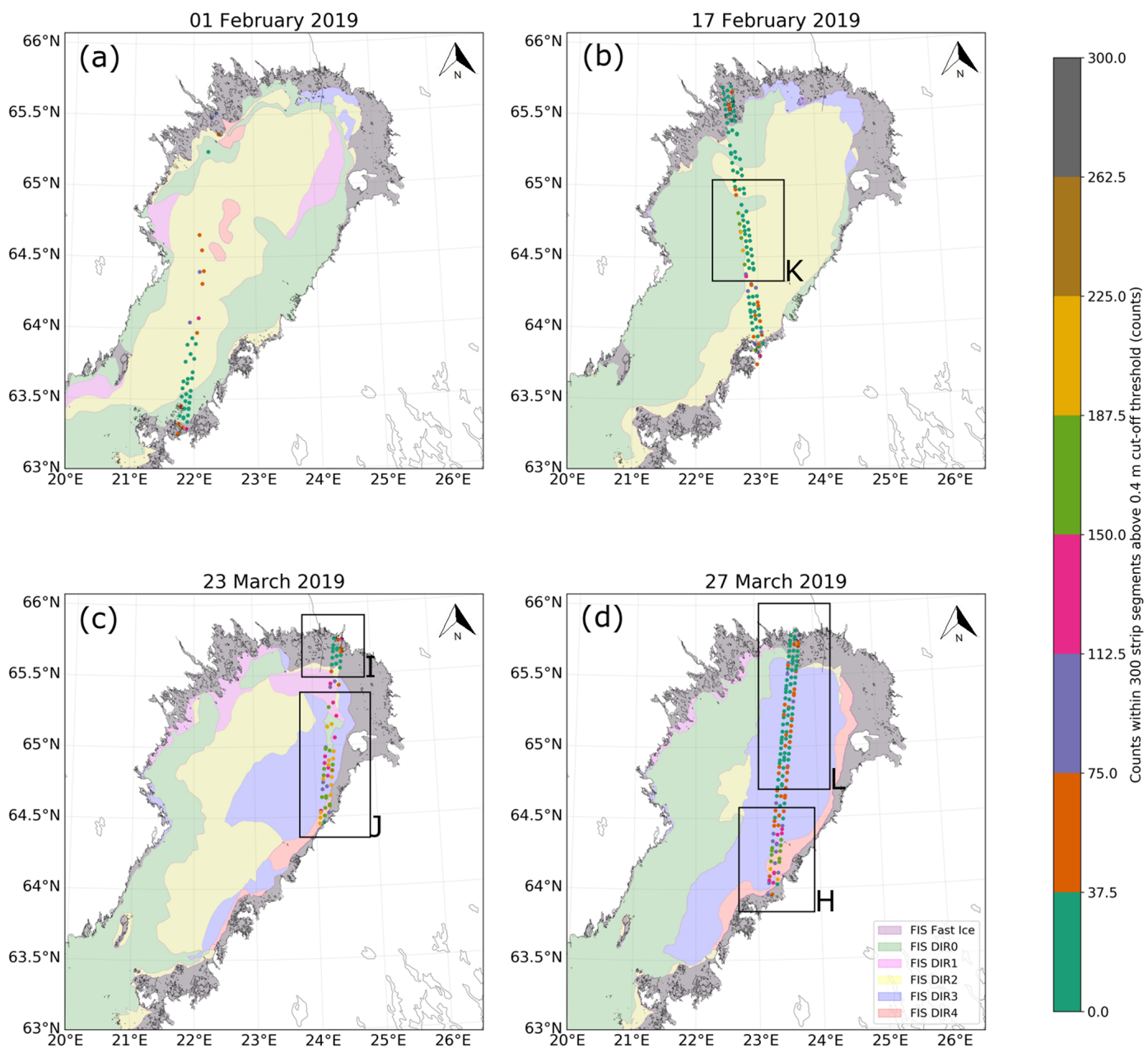

Figure 5. Counts of sails, within aggregated strips of 300 elevation anomalies, with values exceeding $0.4 \mathrm{~m}$, acquired over four available dates (strong beams): (a) 1 February, (b) 17 February, (c) 23 March, and (d) 27 March 2019. Contours show DIR polygons derived from FIS ice charts. Darker areas close to the coast denote fast ice. Colour bar denotes number of elevation anomalies, $h_{\mathrm{a}}$, within a strip of 300 elevation anomalies exceeding $0.4 \mathrm{~m}$ (cut-off height). H-L denote different areas of interest mentioned in the text.

trating the sea ice, causing an increase in the surface roughness (specifically near Region E), but also land contamination could explain this (e.g. regions A-D, F, and G). Thus, in order to automate the estimation of IS2 DIR values to use for daily ice-charting purposes, it would be necessary to look into additional pre-processing steps to exclude the photons disturbed by cloud cover, ocean waves, and land contamination, as these can affect the result. Once identified, these events could be assigned a measure of confidence to warn the ice analyst. Such flags could also be applied to the DIR values affected by background photon events.

Furthermore, although DIR is not uniformly defined and is highly dependent on the ice analysts' interpretation of the provided auxiliary data, such as icebreaker routine reports and SAR imagery, it is widely accepted that DIR is dependent on both amplitude (ridge sails) and spatial distribution of ridges (ridge density). The results presented in Fig. 4 focus on the amplitude of the sea ice roughness and categorise
DIR based on different amplitudes of ridge sail heights. However, the density of ridges is even more important to consider when navigating in ice-covered waters, since the higher the ridge density, the harder it will be to navigate. To investigate the spatial distribution of ridges, we aggregate the elevation anomalies into strips of 300 , thus covering an along-track distance of $\sim 5 \mathrm{~km}$ (assuming an average distance between the elevation anomalies, $h_{\mathrm{a}}$, of $17 \mathrm{~m}$ ). For each of the strips, we count how many of the elevation anomalies exceed a cutoff height of $0.4 \mathrm{~m}$, which would indicate a ridge in ice conditions encountered in the Baltic Sea (Lewis et al., 1993). The distribution of the number of elevation anomalies above the cut-off height within a strip of 300 elevation anomalies is provided in Fig. 5. A small number of counts (green and light purple colours, e.g. most of the track in Fig. 5a) represent areas associated with a low ridge density, which is to be expected over lower-DIR areas. Regions of particular interest are denoted by letters $\mathrm{H}-\mathrm{K}$ in Fig. 5. In Region $\mathrm{H}$, the higher 
ridge densities coincide with the highest-DIR area, i.e. DIR4. The count for one strip in Region $\mathrm{H}$ is around $75-225$ out of the 300 elevation anomalies, which (by using a value of 180 counts per $\sim 5 \mathrm{~km}$ ), is equivalent to 36 ridges per kilometre. In the helicopter-borne electromagnetic (HEM) study utilised in Gegiuc et al. (2018) acquired primarily in March 2011, the authors obtained measurements in the eastern Baltic that on average provided a ridge density for DIR 4 of 21.5 ridges per kilometre. Hence, the ridge densities for DIR4 obtained by IS2 are higher compared to the average of the HEM study of Gegiuc et al. (2018). However, the ridge densities for IS2 DIR4 are to be expected, since the HEM study encountered ridge densities in the range of $0-50$ ridges per $1 \times 1$ nautical mile (NM) cells ( $1 \mathrm{NM}=1852 \mathrm{~m})$ (Gegiuc et al., 2018).

Region I shows very low count values, which is to be expected as the track covers fast-ice regions. This is also visible as low amplitudes (low ridge sail heights) in the same area (Region C) in Fig. 4. In Region J, there is a high spatial density of ridges with high sail heights (Fig. 4c) even though, according to the ice charts, the track does not coincide with DIR4 areas; i.e. the lowest-DIR area the track coincides with is DIR3. However, the count values of Fig. $5 \mathrm{c}$ are even higher than in Region $\mathrm{H}$.

This can be explained by the measured sea ice being located close to the coast and/or the fast-ice region and by the typical drift pattern in the Bay of Bothnia causing the sea ice to be pushed towards the eastern part of the bay (near the island of Hailuoto; see Fig. 1 for precise location). Thus, the deformation of sea ice will be rougher - and most likely result in higher sails (Fig. 4b) - which would explain the higher counts in Fig. 5c. Finally, Region K shows a part of the track that suddenly experiences high counts over low-DIR areas, which are similar to the amplitude values in Fig. 4b. As has already been mentioned, this may be due to unfiltered photons from background sun events or cloud cover, i.e. noise photons. The effect of ocean waves of significant height (above the cut-off height) has not been investigated here but should not be neglected, as studies have shown how IS2 photons can identify waves (e.g. Klotz et al., 2020; Horvat et al., 2020). We do acknowledge that it is not unlikely that ocean waves will occur in this area and could be above the cut-off height, as the area (on the left of the yellow polygon in Fig. 5b) is classified as very open ice in the FIS ice chart, and the impact should be investigated in future studies.

Region L (Fig. 5d) represents one of the longest transects over a high-DIR zone (DIR3); however this is not well reflected in the associated ridge densities, where the counts are less than 100 and more often less than 50. It is also seen, in Fig. 4d, how IS2 DIR2 was the prominent DIR zone here, whereas FIS had identified it as DIR3. This could be caused by e.g. a relatively small variation in the elevation anomalies of the sea ice cover, even though it was identified as DIR3 by the ice analyst from the analysis of SAR images. We reiterate that the ice charts have a lower resolution compared to IS2, meaning that areas with high-FIS-DIR zones cannot necessarily be expected to have the same DIR occurring everywhere in the associated IS2 observations due to the different resolutions. We will further investigate these unexpected cases in Sect. 3.2.

\subsection{Comparison of SAR and IS2 data}

The cases to be studied here, highlighted also in Figs. 4 and 5 , are listed in Table 3, with the respective specifications of IS2 and FIS DIR (or IS2 ridge densities/counts).

Regions A, C, D, F, G, and I are all regions classified as fast ice in the FIS ice charts. Hence, there should be no DIR values identified by IS2 (Fig. 4) or very few counts (0-50, Fig. 5). This is in line with our results, as presented in Table 3. For some of these regions, IS2 does encounter DIR4 values due to land contamination (Fig. 4). As we already pointed out in Sect. 3.1, these outliers could be removed with a detailed land mask, and we will not investigate these cases further here. Regions B and H represent the same area and are essentially observing the same behaviour (high FIS DIR, high IS2 DIR, high IS2 ridge densities/counts); thus we will only look at this region with a focus on IS2 DIR (Region B), and not on the IS2 proxy for ridge density. Regions E and $\mathrm{K}$ also represent the same areas and experience similar behaviour; however the behaviour is not as expected (low FIS DIR, high IS2 DIR, high IS2 ridge densities/counts). Since IS2 DIR and ridge densities both observe the same behaviour, we will only look at the region from the perspective of IS2 DIR (Region E).

Thus, apart from the cases causing differences due to land contamination (A, C, D, F, G, I) the results yield four cases to be further investigated, i.e. regions B, E, J, and L. For this purpose, each of the cases will be compared with a nearcoincident SAR image (SI-SIII), and their individual photon profile will be compared with elevation anomalies (P1P4); see Table 3 and Figs. 6 and 7. The SAR frames presented in Fig. 6 are all provided in HV polarisation, as this tends to be the most optimal combination to resolve deformation features. Some of the SAR frames for regions SII and SIII are also presented in HH polarisation (Fig. 8) to better discriminate between ice and open water/thin ice. In general, high backscatter (bright colours) corresponds to deformed ice (rough ice) in HV SAR frames and low backscatter (dark colours) corresponds to open water/thin ice in $\mathrm{HH}$ SAR frames.

Region E on 17 February 2019 covering FIS DIR1-DIR2 but identified as DIR2-DIR4 in IS2 has been investigated in more detail. The IS2 DIR within the FIS DIR2 zone is also identified as DIR2 in IS2. However, on the border of FIS DIR1-DIR2, the elevation anomalies from IS2 has been identified as DIR3-DIR4, which warrants further investigation. If we look at the photon profiles (P4) in Fig. 7a, we see that the high elevation anomalies stem from a large amount of subsurface scattering (high-density subsurface photon cloud) 
Table 3. Overview of the investigation of cases. ${ }^{*}$ Cases based on proxy for ridge densities, in Fig. 5.

\begin{tabular}{llllll}
\hline Region & Date & FIS DIR & IS2 DIR or counts* & $\begin{array}{l}\text { Photon } \\
\text { profile }\end{array}$ & $\begin{array}{l}\text { SAR } \\
\text { image }\end{array}$ \\
\hline A & $27 / 03$ & Fast ice & DIR4 & - & - \\
$\mathrm{B}$ & $27 / 03$ & Fast ice, DIR3-DIR4 & $\begin{array}{l}\text { DIR3-DIR4 } \\
\text { C1 }\end{array}$ & SI \\
D & $23 / 03$ & Fast ice & DIR4 & - & - \\
E & $17 / 02$ & Fast ice & DIR4 & - & - \\
F & $17 / 02$ & DIR1-DIR2 & DIR2-DIR4 & P4 & SIII \\
G & $01 / 02$ & Fast ice & DIR4 & - & - \\
\hline $\mathrm{H}^{*}$ & $01 / 02$ & Fast ice & DIR4 & - & - \\
$\mathrm{I}^{*}$ & $27 / 03$ & DIR3-DIR4 & $75-225$ & - & - \\
$\mathrm{J}^{*}$ & $23 / 03$ & Fast ice & $0-75$ & - & - \\
$\mathrm{K}^{*}$ & $23 / 03$ & DIR0-DIR1, DIR3 & $75-262.5$ & $\mathrm{P} 3$ & SII \\
$\mathrm{L}^{*}$ & $17 / 02$ & DIR1-DIR2 & $0-225$ & - & - \\
\hline
\end{tabular}

in strong beam GT1L. In the ATL03 Known Issues document (https://nsidc.org/sites/nsidc.org/files/technical-references/ ICESat2_ATL03_Known_Issues_v003_Aug2020.pdf, last access: 18 February 2021), this phenomenon has been attributed to multiple scattering which can occur over surfaces with e.g. heavy blowing snow or dense fog. This results in a widening of the surface return with more photons erroneously occurring from under the actual surface. We have retrieved observations on wind speed in the Bay of Bothnia from the weather station at Kemi (Ajos), located at $65.67^{\circ} \mathrm{N}, 24.52^{\circ} \mathrm{E}$, provided by FMI (https://en.ilmatieteenlaitos.fi/download-observations, last access: 18 February 2021). The wind speed was $8 \mathrm{~m} \mathrm{~s}^{-1}$ on average at the weather station on 17 February 2019; temperature was well below zero, and relative moisture content was $90 \%$. In the hours (04:00-10:00) around IS2 acquisition time (07:44:19; see Table 1), the average wind speed was $10 \mathrm{~m} \mathrm{~s}^{-1}$. This could indicate the subsurface scattering being caused by blowing snow or Arctic steam fog over open water, but there is no way to confirm this. Potentially, the IS2 DIR identified as DIR3-DIR4 could also stem from ocean waves (as suggested in Sect. 3.1). To investigate what surface type is observed by IS 2 around the time of acquisition, e.g. low ice concentration/open water compared to ice cover, we have extracted a SAR frame for comparison (SIII in HV and HH polarisation in Figs. 6a and $7 \mathrm{a}$, respectively). From the SAR frame, it is clear that over the ice, small variations in the IS2 elevation anomalies are observed over less deformed ice (low backscatter), and areas over more deformed ice (higher backscatter) experience an increase in elevation anomalies. The beam track (GT1L) measures what in the SAR image appears dark, where most of the high elevation anomalies occur. We emphasise that the subsurface scattering/multiple scattering likely caused by heavy blowing snow has not been accounted for in this methodology yet and will affect the results if the density of the subsurface photons is high, which will affect the overall average value of an aggregated 150-photon segment. It has been noted as a known issue in the ATL03 data product, and should be mitigated should one aim to use the elevation anomalies (or IS2 DIR classifications presented here) for ice-charting purposes.

Region J has been investigated with a photon profile (P3) and by comparison with SAR imagery (SII); see Figs. 6b and $7 \mathrm{~b}$. This region experienced differences in FIS DIR zones (DIR0-DIR1 and DIR3), but many of the elevation anomalies detected by IS2 identified DIR3-DIR4 in this region. In particular, over FIS DIR0, IS2 DIR3 was identified (Fig. 4). In SII (Fig. 6b), we see a correlation between high backscatter (bright colours) and higher elevation anomalies. Furthermore, the photon profile (P3, Fig. 7b) does not appear to experience a lot of subsurface returns (multiple scattering), as was the case for Region E. Here we also use $\mathrm{HH}$ polarisation SAR data; see Fig. 8b. From Fig. 8b, it can be seen that for areas of low backscatter, the elevation anomalies are lower.

Region L on the 27 March 2019, covering FIS DIR3, which encountered very few "ridge counts" (or low IS2 DIR above DIR2) warrants further investigation. A photon profile (P2) has been extracted, and the elevation anomalies are compared with an S1 image (SI) (Figs. 6c and 7c). Note here that the photon cloud (P2) is biased high for latitudes larger than $65.3^{\circ} \mathrm{N}$, caused by the differences between the actual sea surface height and the geoid. This bias is eliminated in the pre-processing step as described in Sect. 2.4 and will not affect the final elevation anomalies. While FIS DIR states it to be DIR3, both the IS2 elevation anomalies and the SAR image (SI) do not indicate significant ridging and/or deformation (high backscatter shown by white areas). The photon profile generally does not have significant multiple subsurface scattering, and the few higher elevation anomalies identified follow the photons identified at high elevations. Generally, this indicates that IS2 DIR is following the actual local 

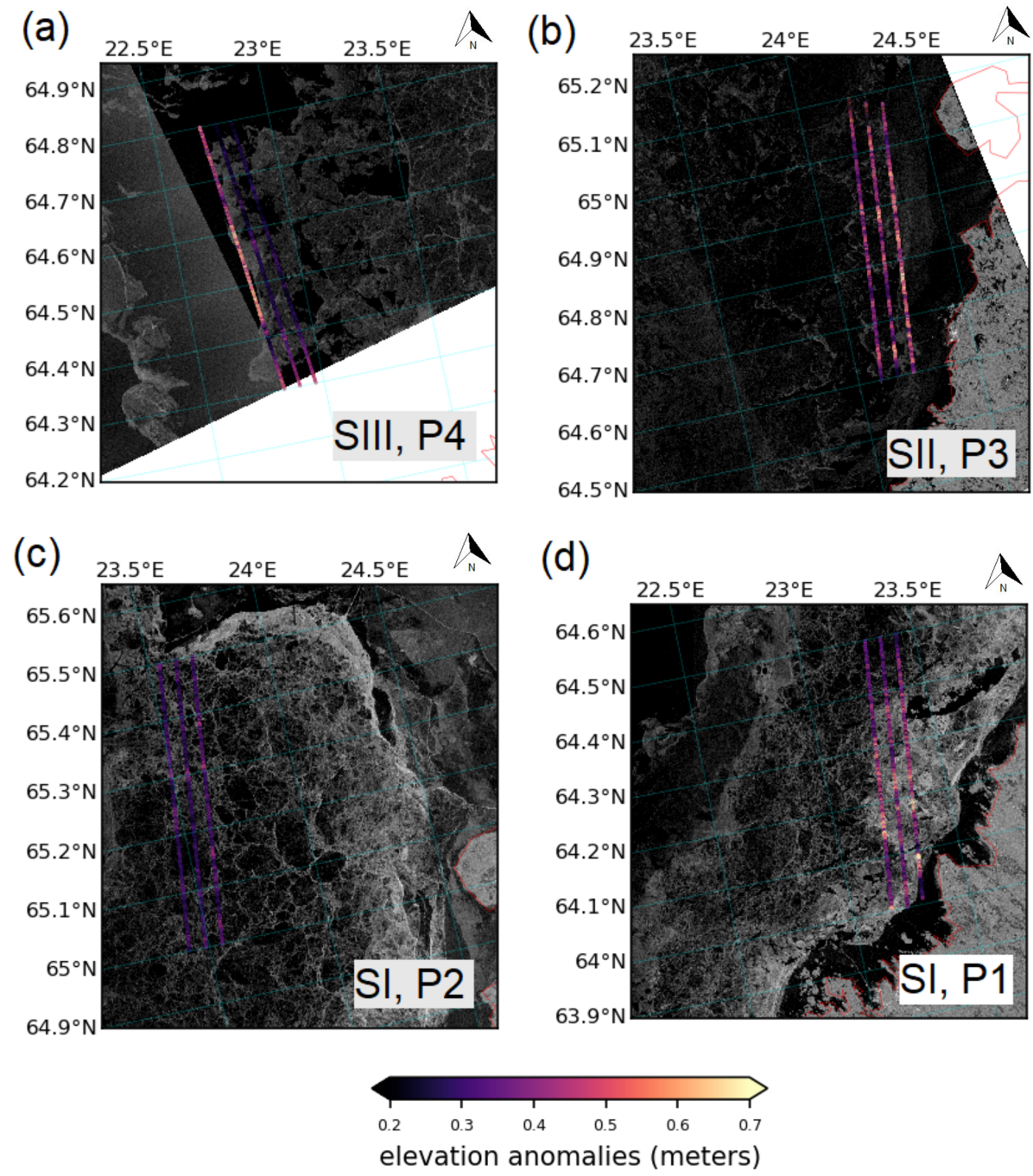

Figure 6. Elevation anomalies overlaid on an S1 SAR image (SI-SII in HV polarisation) for four cases (see Tables 1 and 3 for specifications; the figures represent the (a) case for Region E on 17 February 2019, (b) case for Region J on 23 March 2019, (c) case for Region L on 27 March 2019, and (d) case for Region B on 27 March 2019; P1-P4 highlight the relative photon profiles to be found in Fig. 7). Strong backscatter (white areas in SAR image) is usually perceived as deformed ice in HV polarisation.

ice distribution and that the DIR category from FIS is based on the larger-scale sea ice conditions and not on the smallscale roughness as observed by SAR (SI) and the IS2 elevation anomalies (Figs. 6c and 7c).

Region B on the 27 March 2019, which covered both fast ice and DIR3-DIR4 in the FIS ice chart, was identified as DIR3-DIR4 in IS2 DIR and is compared with an S1 image (SI) and the photon profile (P1); see Table 3 and Figs. 6d and $7 \mathrm{~d}$. Here, a correlation between high backscatter (white areas) with high elevation anomalies (bright colours) is seen. Similarly, over the fast-ice region (dark area, low backscatter) near the coast, lower-elevation anomalies are observed. Generally, here the elevation anomalies follow the surface roughness observed in the SAR image (SI) with rough, deformed areas (large backscatter) having higher elevation anomalies.

\subsection{Implications for IS2 and future work}

\subsubsection{Impact of cloud cover}

Our study is limited, as at the time of submission, IS2 data for 2019/20 were not completely available yet. Even if they were, 2019/20 was an exceptionally mild winter in our test area, and we would expect to find very few usable overpasses of IS2 over ridged ice. Throughout January to March 2019, only 25 granules of data passing the Bothnian Bay were available (which were either not or only partly affected by clouds to be removed by pre-processing steps, determined by visual inspection). During April-May (until 14 May where 
(a)
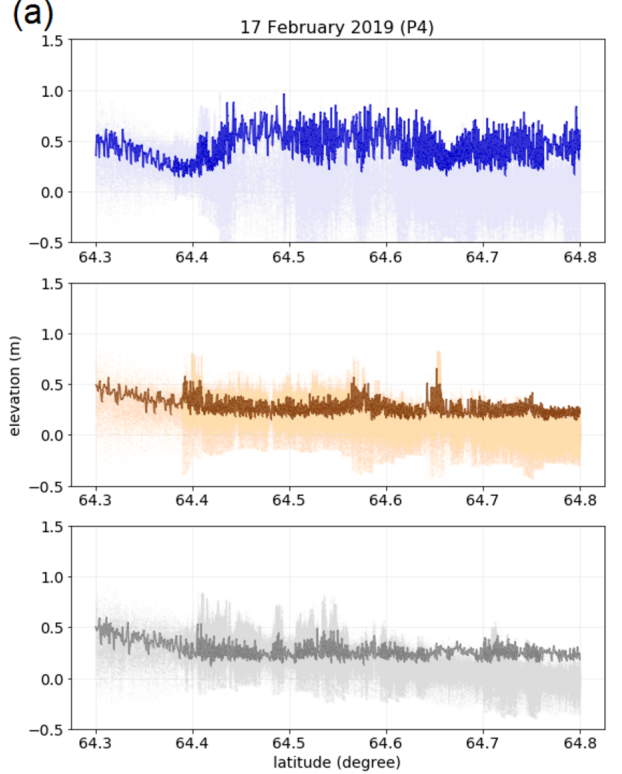

(c)
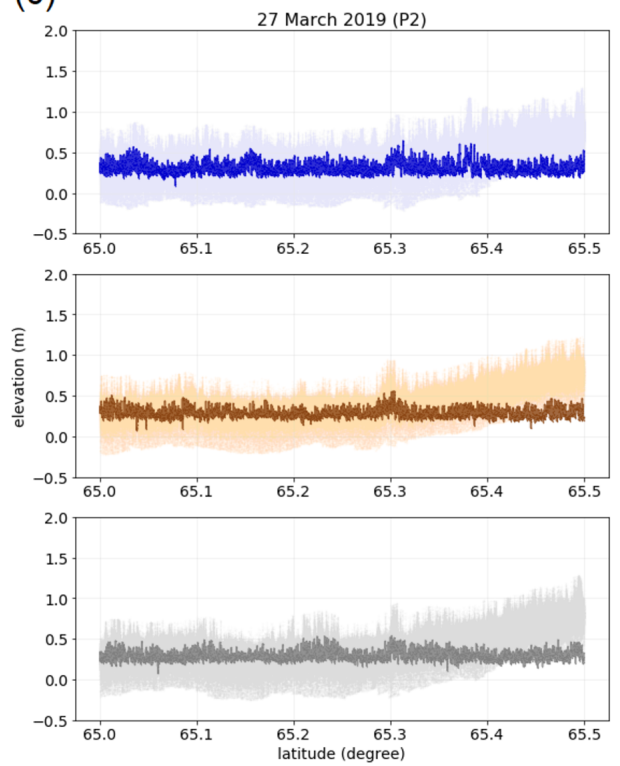

(b)
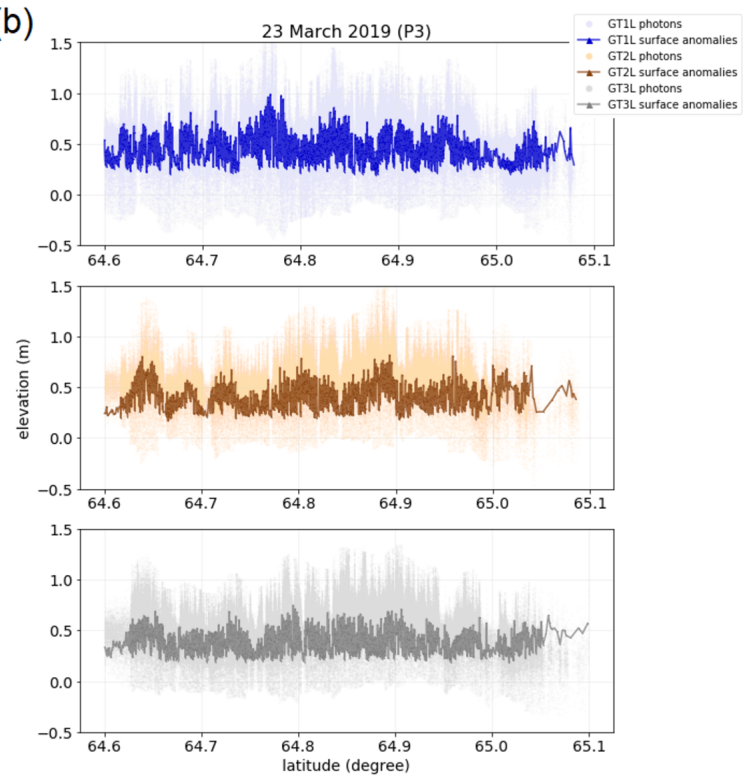

(d)
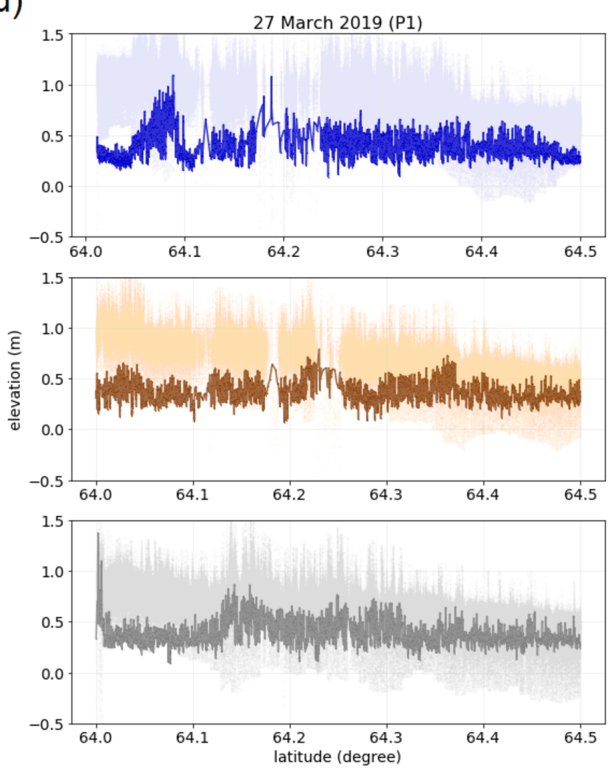

Figure 7. Photon profiles (P1-P4) of strong beams ATL03 photons (separated into each strong beam; GT1L, GT2L, GT3L) with elevation anomalies overlaid for four cases (see Tables 1 and 3 for specifications; the figures are representing (a) case for Region E on 17 February 2019 , (b) case for Region J on 23 March 2019, (c) case for Region L on 27 March 2019 and (d) case for Region B on 27 March 2019).

the ice season ended according to BIM, 2019), only 12 granules were available; however all were affected by cloud cover. Of the 25 granules between January-March, 10 of these were considered "cloud-free" and 15 were considered "partially cloud-disturbed" (Fig. 9), determined by visual inspection. Of the 25 granules, only 4 granules intersected an FIS DIR area to such an extent that a decent number of photons could be extracted and used in this analysis. A harsher ice season would experience more ice formation and deformation, likely causing more granules to intersect with DIR areas. It should be noted that while the data are limited, the
4 granules intersecting a DIR area presented in this study were measured both during the beginning of the ice season, where the weaker and less deformed ice occurred (February, where only DIR2 is registered by the FIS ice charts), and over the more heavily deformed ice (March, where both DIR3 and DIR4 are registered in the FIS ice charts). From Fig. 9 it can be noted that during January-March, it was possible to retrieve data that were either cloud-free or only partially cloud-disturbed, whereas in April-May, no data were able to be retrieved due to persistent cloud cover. Thus, the end of the ice season and ice ridging could not be properly investi- 
(a)

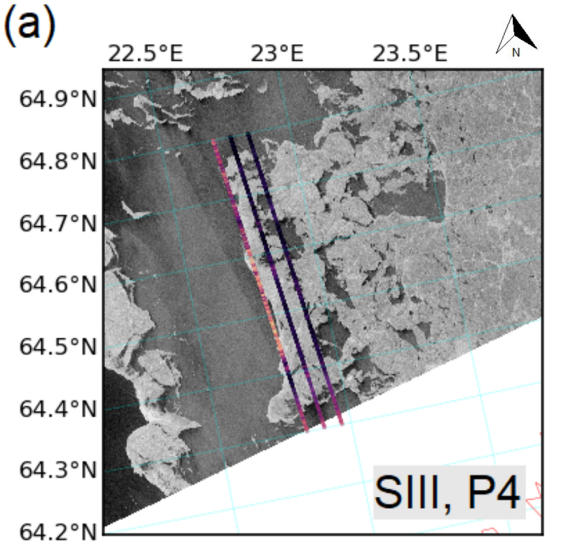

(b)

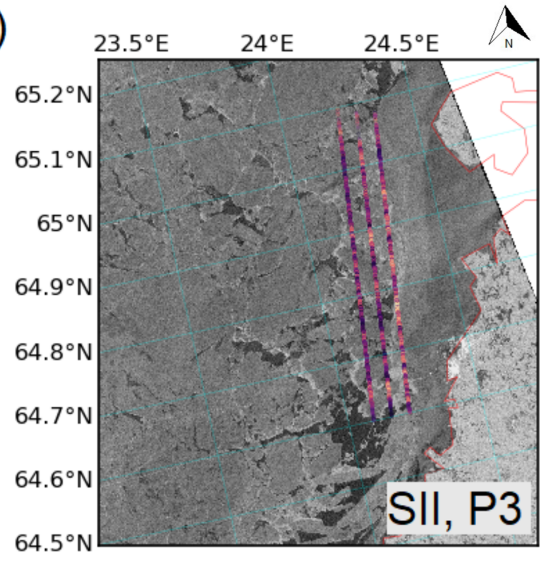

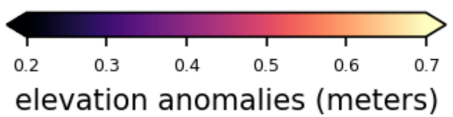

Figure 8. (a) S1 C-band SAR image (SIII, HH polarisation) acquired on 17 February 2019 with elevation anomalies from IS2 overlaid, $8 \mathrm{~h} 5 \mathrm{~min}$ between acquisitions. Similar to Fig. 6a but with different SAR polarisation. (b) S1 C-band SAR image (SII, HH polarisation) acquired 23 March 2019 with elevation anomalies from IS2 overlaid, 2 h 26 min between acquisitions. Similar to Fig. $6 \mathrm{~b}$ but with different SAR polarisation.

\begin{tabular}{|c|c|c|c|c|c|c|c|c|c|c|c|c|c|c|c|c|c|c|c|c|c|c|c|c|c|c|c|c|c|c|c|}
\hline 2019 & 1 & 2 & 3 & 4 & 5 & 6 & 7 & 8 & 9 & 10 & 11 & 12 & 13 & 14 & 15 & 16 & 17 & 18 & 19 & 20 & 21 & 22 & 23 & 24 & 25 & 26 & 27 & 28 & 29 & 30 & 31 \\
\hline January & & & - & & & & ○ & & & & ○ & & & & - & & & & ○ & ○ & & & ○ & 0 & & & & $\circ$ & & & \\
\hline February & 0 & & & & ○ & & & & - & & & & 0 & & & & 0 & ○ & & & 0 & - & & & & • & & & & & \\
\hline March & & ○ & & & & & & & & - & & & & $\bullet$ & & & & • & 0 & & & ○ & 0 & & & ○ & 0 & & & ○ & ๑ \\
\hline April & & & & • & & & & • & & & & $\bullet$ & & & & • & & & & • & - & & & $\bullet$ & - & & & & $\bullet$ & & \\
\hline May & & & ○ & & & & - & & & & ○ & & & & & & & & & & & & & & & & & & & & \\
\hline
\end{tabular}

$$
\begin{aligned}
& \text { End of ice-season (18d) Cloud-disturbed data (16g) } \\
& \text { Intersecting DIR area (4g) ○ Partially cloud-disturbed data (15g) } \\
& \text { - Cloud-free data }(10 \mathrm{~g})
\end{aligned}
$$

Figure 9. Availability of IS2 data granules (tracks) available during spring 2019 (January-May). Each dot represents an available granule which, by visual inspection, is categorised as cloud-disturbed data (blue), partially cloud-disturbed data (orange), or cloud-free data (green). Numbers in parentheses denote number of granules (g) or days (d). Coloured cells denote either end of the ice season (orange), intersecting DIR area (green), or not applicable (grey).

gated. January had surface photons available for all available granules intersecting the Bay of Bothnia; however the deformation of the ice cover was not extensive enough at that time for the ice analysts to claim an area as slightly ridged (DIR2) or higher; thus it was not of particular interest to this study. While IS2 data are impacted a great deal by cloud cover, this study was still able to investigate ridging occurring during the beginning of the ice season, with mild deformation, and towards the middle/end of the ice season, with the highest deformation occurring. Therefore, we assume the granules used in this study represent the ice deformation occurring in the Bay of Bothnia well, albeit during a mild ice season.
The Baltic Sea is relatively small and located south of $66^{\circ} \mathrm{N}$, chosen for this study due to the availability of quality reference data. Nonetheless, this study shows the potential of IS2 data to supplement other sources of information for ice charting. Furthermore, with the expected increase in shipping in the Arctic as a response to the continuing melting of the sea ice cover (e.g. Melia et al., 2016), these results prove valuable not only for the Baltic ice services and ice charting but also for international ice charting. With the increased IS2 coverage in the Arctic, compared to in the Baltic Sea and Bay of Bothnia, more photon elevations and tracks become available, therefore we do not foresee cloud cover as 
much of a restriction in Arctic ridge determination during the winter period (October-April). Increase in cloudiness in the Arctic has been reported in spring (March-May) (Schweiger, 2004), suggesting that spring and likely also summer months will experience an increase in loss of data due to increased amount of cloud cover. The same is observed for the Baltic, as seen in Fig. 9, with no data available from April and on towards the end of the ice season. Even with an increase in clouds during spring and summer, recent studies have shown the first steps in using IS2 observations to estimate melt ponds in the Arctic summer sea ice (Tilling et al., 2020), showcasing that some valuable information can be retrieved by IS2 in the Arctic during summer. Possibly even information on summer sea ice deformation can be retrieved alongside melt ponds.

With the cloud cover impacting the photon product, there could be a great benefit of applying a cloud flag in the preprocessing stage to remove erroneous points originating from clouds. This yields the following question: is there potential for applying cloud flags in the processing? The ATL03 product does not provide a cloud flag, nor do the ATL07 (surface heights) or ATL10 (freeboard) products. Indeed, only the atmosphere product (ATL09) provides a cloud flag; however as stated by Kwok et al. (2021), the resolution of the cloud flags available in ATL09 is too coarse to provide useful filtering (at least at the lead segment scale, $\sim 27-40 \mathrm{~m}$ ). The cloud flags are sampled every $\sim 400 \mathrm{~m}$ (Kwok et al., 2021); hence the resolution of the cloud flags will also be too coarse to use over deformed sea ice (determined by DIR from elevation anomalies, calculated on average every $\sim 17 \mathrm{~m}$ ). Should ATL03 in the future be provided with quality flags useful for removing photons impacted by clouds, this would have great benefit for methods using the lower-level ATL03 photon data product, such as that presented in this study.

\subsubsection{Ridge anisotropy in the Bay of Bothnia}

The ice charts do not include the orientation of ridges. As IS2 data are transect data by nature, isotropy of ridge orientation would complicate the comparison. The ridge orientation has been studied by the FIS in the past, and the conclusion was that in the vicinity of the landfast ice, the preferred orientation of ridges is the local direction of the coastline. However, further away the ridge orientation is anisotropic (see Fig. 10). Most of the IS2 data used in this study are located far from the zone where orientation isotropy is found. Thus, our study is not significantly affected by ridge orientation. However, in future studies, the presence of preferred ridge orientation could be detected from differences in ridge densities between ascending and descending orbits. The orbit in the direction of the preferred ridge orientation should measure lower ridge density than the one perpendicular to it. However, an absence of cloud cover would be necessary to ensure that both ascending and descending tracks are available without cloudcontaminated photons.

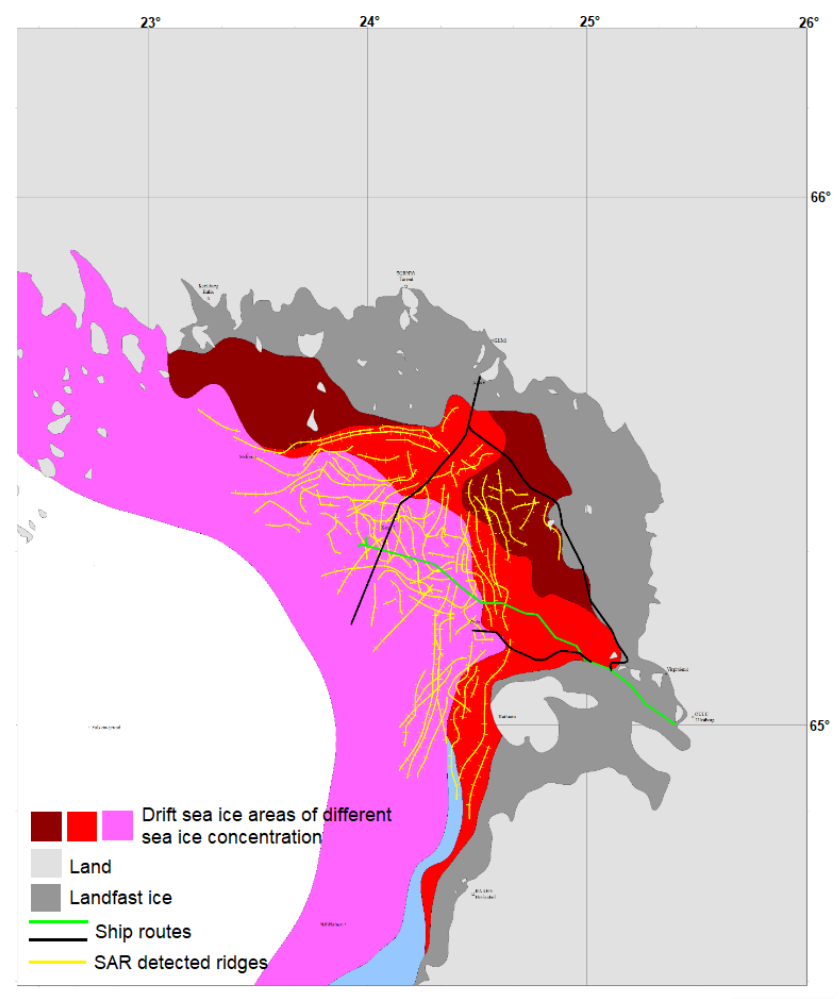

Figure 10. Ridges close to the ports of Oulu and Kemi, winter 2013/14. Courtesy of the FIS and Finnish Transport Infrastructure Agency. Note that only the ridges falling within the area of ship channels (black and green lines) were analysed.

\subsubsection{Ice floes and impact in low-ice-concentration areas}

Potentially, a higher elevation anomaly could be due to sudden changes in surface: the drop in elevation between ice floes and sea surface. We reiterate that the elevation anomalies are based on the difference between the highest elevation within a segment and the average value of that particular segment. In that regard, if the segment of 150 photons occurs over a change in surface types (ice floes vs. open water), potentially the highest elevation anomaly could originate from the top of the ice floe (where snow could also introduce additional scattering, potentially increasing the elevation of the photon), and the average value of the segment could be influenced by photons from the sea surface, which generally has lower elevations compared to ice floes. Thus, the impact of low-ice-concentration areas, as the surfaces here will range between ice floes and sea surface more often, warrants more investigation, although it is out of the scope of this study. Potentially, one could argue that the ridge identification and sea ice deformation information retrievable from IS2 should only apply in areas where sea ice concentration exceeds $70 \%$, which is a common threshold applied to altimetry-derived sea ice thickness due to the difficulties of 
retrieval of sea ice freeboard over areas of low sea ice concentration. However, this also suggests that a combination of IS2 data (potentially the elevation anomalies or IS2 DIR identification scheme presented here) and SAR images can provide interesting and important information for the ice analysts. SAR images can provide the overall sea ice distribution and deformation, whereas IS2 can be used over particular deformed areas to identify the impact of the ridging by providing the height of the ridge sails. Potentially, combining the data with high-resolution optical images could help identify which surface IS2 encounters as well. A study by Petty et al. (2021) has linked Sentinel-2 (S2) optical imagery with IS2 (ATL07/ATL10) to estimate e.g. chord length of the ice floes. Hence, combining ATL03 with S2 (and/or Sentinel-3) optical imagery could also provide useful insight into surface classifications, and optical images are also interesting in combination with IS2 due to the impact of cloud cover that affects both laser and optical acquisitions.

\subsubsection{Impact of noise photons in the methodology used}

Throughout this paper, we work under the assumption that the highest photon elevations within a segment originate from a ridge sail. There is a possibility that they actually originate from a background sunlight event, fog, blowing snow, or cloud cover. Nonetheless, we find the overall elevation anomalies correspond with expected sail heights in the area, and it therefore seems likely that the confidence flag in the ATL03 product is of very good quality.

To evaluate the impact of possible noise photons being the highest measured elevation within a 150-photon segments, we investigated percentiles of the segments with the mean value subtracted from each of the elevations, rather than with the mean elevation subtracted from the highest elevation (the elevation anomaly, $h_{\mathrm{a}}$ ). Thresholds based on the 98th percentile of the mean subtracted from the photon elevations rather than on $h_{\mathrm{a}}$ (see Table 2) have similar intervals (about $0.10 \mathrm{~m}$ smaller for each interval); however the distributions of the classified DIR zones are similar to those of the elevation anomalies (as presented in Fig. 4). This suggests that even by using only high-confidence photons and the highest value, in most cases the photons do in fact originate from the top of the ridges. Hence, for ridge sails that are less than $1 \mathrm{~m}$ in height, the onboard filtration scheme of low-, medium-, and high-confidence photons seems to keep only surface photons including photons originating from the top of the ridge sails and successfully removes noise photons. Using the 98th percentile instead of $h_{\mathrm{a}}$ excludes approximately 3 photons per 150-photon segment; thus due to dead time and the single photon-counting method of IS2 (Neumann et al., 2019b), the top of the ridge may not be included if the highest photon of the segment is excluded. However, the 98th-percentile thresholds are also within the range of average ridge sail heights determined by former studies (of $0.5-0.6 \mathrm{~m}$; see e.g. Lewis et al., 1993; Gegiuc et al., 2018). Further validation of ridge sails and surface measurements of small-scale roughness, such as ridges in the Baltic Sea, observed by IS2 by comparing with airborne observations is encouraged.

Furthermore, it should be noted that this study utilises version 2 (v2) of the ATL03 product (Neumann et al., 2019a). ATL03 was upgraded to version 3 (v3) in May 2020, but due to reprocessing and processing lags, there might be gaps in the v3 data. Hence, we have kept using v2 data, especially since the updates of $\mathrm{v} 3$ do not seem to impact our data significantly. Four major updates were presented in v3 (see https://nsidc.org/data/at103, last access: 23 April 2021, "Version Summary"):

- v3_1. A quality assessment parameter indicating the percentage of reference photons within a certain distance from the reference digital elevation model (DEM) has been introduced.

- v3_2. Photons that do not intersect the DEM height within a $\pm 30 \mathrm{~m}$ buffer are effectively removed from consideration by the signal classification processing. Furthermore, photons that are poorly geolocated (provided by a new flag, podppd_flag) are no longer classified as a potential signal.

- v3_3. A logic error in the code combining the precise orbit determination (POD) and precise pointing determination (PPD) degrade values has been fixed, and a flag (podppd_flag) has been introduced.

- v3_4. Finally, two new parameters indicating nearly (near_sat_frac) or fully (full_sat_frac) saturated ATLAS shots have been introduced.

The updates v3_1-v3_2 will generally affect the number of photons to be removed in the pre-processing stage $( \pm 3 \mathrm{~m}$ from the geoid elevation); however there will not have a significant impact on the results; i.e. the signal photons should not be removed by the $\pm 30 \mathrm{~m}$ from DEM buffer introduced in v3_2. The podppd_flag (v3_3) could potentially remove badly geolocated photons that are still within the $\pm 3 \mathrm{~m}$ from geoid elevation buffer that is applied in the pre-processing step of this study. However, we assume this to be of small significance. If a few photons within the photon cloud are badly located, it will have a small impact on the average value (used to calculate elevation anomalies), and if a badly geolocated photon turns out to be the highest value within a segment (used in calculating the elevation anomaly), it could potentially be mitigated by using e.g. the 98th percentile instead of the highest photon (as described at the beginning of Sect. 3.3.4). Potentially, the two new parameters (explaining near and full saturation of ATLAS, v3_4) could be used to further process the data (e.g. mitigate the effect of a firstphoton bias that the photon-counting lidar is affected by see e.g. Sect. 7.7.3 in Neumann et al., 2020 - usually applied to higher-level products). When ATLAS is fully saturated, the surface return photons will show a gap in height 
with no reported photons for the duration of the detector dead time. However, it is stated in Neumann et al. (2020) that in the cases where near or full saturation of ATLAS proves difficult and requires special handling are mostly related to higher-level products (ATL03+). For future work, v3 will be used, and future quality assessment indicators could potentially be included to aid the pre-processing and remove erroneous point measurements, e.g. photons originating from clouds or multiple surface scattering, should a future quality indicator on this aspect be provided in the ATL03 product. Nonetheless, we found v2 of ATL03 used in this study to be of high quality already.

\subsubsection{Uncertainty in IS2 DIR}

Currently, the IS2 DIR intervals are based on the selection of elevation anomalies originating from different FIS DIR areas, and at a later stage the computed IS2 DIR are compared to the same FIS DIR. However, the resolution of FIS DIR is quite coarse; thus a direct validation in terms of e.g. a confusion matrix that would show exactly how many IS2 DIR observations were correctly/falsely classified within FIS DIR polygons is to some extent useless. This is also why we do not aim to say that this comparison with the FIS DIR constitutes a real validation but rather a comparison with the polygons used to identify different IS2 DIR intervals. However, this raises the question of whether training data by the same polygons also prove useless due to the coarse resolution. IS2 provides sub-scale information (compared to FIS DIR), and by comparing with SAR images, we can identify if the classifications of IS2 DIR (based on elevation anomalies) actually follow the ridging and deformation pattern of the Baltic. This will indicate whether training with FIS DIR for IS2 DIR seems feasible, as the FIS DIR polygons are based partly on icebreaker observations and partly on SAR images. Based on comparison with S1 SAR images, we show that the elevation anomalies correspond to surface roughness (e.g. expected ridge sails in the Baltic) and that the surface information available from IS2 is detailed (high elevation anomalies identified over high backscatter in HV SAR images - see e.g. Fig. $6 \mathrm{~d}$ - which is usually an indicator of sea ice deformation). However, since the classification of this study is based only on the $5 \%$ highest elevation anomalies, either more FIS DIR data or more quantitative S1 data should be included and used for training to ensure robust classification.

However, this raises a different point: the potential of performing quantitative validation with S1. For now, we have performed qualitative validation by comparing the elevation anomalies with S1 SAR images. Potentially, a quantitative validation could be made with both the elevation anomalies and the identified IS2 DIR with the S1 SAR images to see if this qualitative relationship can be validated quantitatively. However, for a comprehensive quantitative validation with $\mathrm{S} 1$, it would be necessary to (1) correct the observations for the sea ice drift occurring between S1 and IS2 acquisitions $(\sim 0.10-0.45 \mathrm{~d}$; see Table 1$)$ and (2) take into account the different spatial resolutions so that the resolution of the IS2 DIR/elevation anomalies fit with the resolution of S1. Drift products in the Baltic are limited to buoy data (sparsely distributed in the Baltic but available in the the Bay of Bothnia, e.g. Karvonen, 2012) and SAR-based drift products (Karvonen, 2012; Karvonen et al., 2020); however the quality of the SAR-based product is limited. The drift is given only between different time instants corresponding to the SAR acquisition times for each of the overlapping SAR pairs. Furthermore, there are several areas where no data exist due to the algorithm not being able to reliably detect ice drift everywhere. Furthermore, there is some error in the ice drift estimation in the current algorithm, as it tends to underestimate the ice drift magnitude (Juha Karvonen, personal communication, May 2020). The limitations of the ice drift product and re-sampling to the same resolution makes the comparison between S1 and IS2 additional work that is out of the scope of this study.

However, even with the limitations described above, a large amount of ice information is retrievable from IS2 photons, as indicated by this study, and more work should be invested into utilising IS2 data for more than just conventional freeboard-to-thickness estimations. Our goal was to show how the IS2 data perform over different ice regimes, in addition to the regions used to train the algorithm, and illustrate how IS2 data might augment the information in the ice charts. By comparison with S1 SAR images, we have shown how small-scale roughness information is available from IS2 - which is otherwise non-retrievable from other altimeters whose footprints and sampling frequencies do not allow for the high-density surface sampling that IS2 does. Furthermore, the comparisons of IS2 and S1 have shown how it is possible to identify deformation occurring over different ice regimes by differences in the magnitude of elevation anomalies. Finally, we have presented one method for how this IS2 small-scale roughness information could be converted into something of use for ice navigators (IS2 DIR) - albeit more work is necessary to refine this methodology, as has been discussed throughout Sect. 3.

\subsection{Future outlook}

We have emphasised the need for a near-real-time or fastdelivery photon product before (Sect. 3.1), but it should be mentioned that even without time-critical products, it would still be valuable to estimate the ice conditions in certain areas for planning purposes. An example of such planning would be compiling the statistical information on ice conditions required by the International Maritime Organization (IMO) Polar Code to create a regional climatology (IMO, 2020). IS2 would then be an independent source of ridging estimates in the ships' planned operation areas.

Currently, the data latency of the ATL03 data product is $21 \mathrm{~d}$ (Brown et al., 2016). Should a near-real-time or a fast- 
delivery photon product become available, IS2 data could be used by operational ice services. Information on ice surface elevation is of high priority to support safe ice navigation not only in the Bay of Bothnia but also across the Arctic. Due to the along-track nature of IS2 measurements, they are most useful when combined with image type data. The main information of ice services at the moment is satellite SAR imagery. However, because there are several processes contributing to SAR backscatter, estimating the ice type from SAR data is necessarily an ambiguous process. Areas of high backscatter are often interpreted as strongly deformed areas. Alas, high backscatter can also result from centimetre-scale surface roughness (Manninen, 1997), for example from frost flowers that are of the magnitude of the SAR wavelength on top of thin new ice. These two properties of ice, which are similar in SAR data, are different from the viewpoint of ice navigation. For the FIS, regular reports from icebreakers are used to support the analysis of SAR frames. In areas where these reports are not available, IS2 would provide a potentially valuable estimate of ridging.

In addition to data latency, usability of ICESat-2 in operational ice charting is also affected by data availability. Measurements are limited to the cloud-free portions of the orbit pattern, and an in-depth explanation of data availability in our study can be found in Sect. 3.3.1. However, we emphasise that in many remote areas where in situ observations are not available, the IS2-based estimates of ridging may be the only option independent of SAR frames.

\section{Conclusions}

In this study, we have presented the correspondence between FIS DIR, satellite SAR data, and elevation anomalies using geolocated photons heights (ATL03) measured by IS2 during spring 2019 in the Bay of Bothnia. DIR derived from IS2 using our methodology follows the general expectations in the Baltic. This is the first time the feasibility of IS2 has been studied from the viewpoint of winter navigation and operational ice charting. DIR is one of the most important parameters used in ice navigation as it indicates whether or not a vessel can safely pass through an ice-covered area. In the Baltic, daily ice charts provided by the FIS include information on DIR based primarily on in situ icebreaker observations and partly derived from SAR imagery.

Furthermore, we find that in some cases (in particular three out of the five highlighted areas) along-track densities of relative elevations (elevation anomaly, $h_{\mathrm{a}}$ ) above a threshold cutoff height of $0.4 \mathrm{~m}$ are consistent with the distributions of the FIS DIR areas. Heavy deformation is found on sea ice close to the coast and/or fast-ice regions. This is expected due to the sea ice drift pattern in the Baltic pushing ice floes towards the coast causing deformation. Typical ridge densities and sail heights expected in the Bay of Bothnia correspond well to the elevation anomalies.
In addition, this study demonstrates how much surface topography information of small-scale roughness $(<1 \mathrm{~m})$ is measured by IS2 and kept, even when applying the highconfidence flag of the onboard filtering scheme. Thus, even over the thin sea ice areas of the Baltic Sea, one can benefit from the high-density surface sampling and information that IS2 provides. Compared with S1 SAR images, the elevation anomalies follow the deformation observed in the SAR images. We note that this methodology of estimating IS2 DIR is based on the highest $5 \%$ of the elevation anomalies, and that while the IS2 DIR follows the deformation seen in the SAR frames (qualitative assessment), the IS2 DIR only follows FIS DIR for some cases. To develop a reliable DIR level classification algorithm from IS2, more FIS DIR observations or quantitative SAR data should be included. We conclude that a time-critical IS2 product would be of benefit to ice services around the world complementing widely used satellite SAR data.

Code and data availability. All data can be obtained by contacting the first author. ATL03 products were retrieved from NASA's Earthdata Search at https://search.earthdata.nasa.gov/ (last access: 18 April 2020), using version 2 (Neumann et al., 2019a). S1 frames were processed by ESA and are available from the Alaska Satellite Facility at https://search.asf.alaska.edu/\#/ (last access: 18 February 2021, NASA EarthData, 2021). Ice charts were provided by the FIS. Shapefiles to produce the map of the Baltic Sea (Fig. 1) were retrieved from HELCOM and are available for download at http://maps.helcom.fi/website/mapservice/ (last access: 21 October 2020, HELCOM, 2021). Scripts used in the data analysis are available online at the following GitHub repository: https://github.com/reneefredensborg/DIR-from-IS2 (last access: 25 March 2021, https://doi.org/10.5281/zenodo.4636435; Fredensborg Hansen, 2021).

Author contributions. RFH, ER, and HS conceived the concept of the study. Processing and computing was performed by RFH. RFH, $\mathrm{ER}$, and HS jointly analysed the data, and SF joined in on discussions in relation to these analyses. RFH wrote the initial manuscript, and all authors contributed to the editing of the text.

Competing interests. The authors declare that they have no competing interests.

Acknowledgements. We thank the FIS for providing their ice charts and expert advice, the Polar Oceanography and Sea Ice group at the Finnish Meteorological Institute for a great discussion and for interesting questions relevant to this study, and Kyle Duncan for useful insights into using IS2 for ridge detection in the Arctic. We thank the two anonymous reviewers and our editor for valuable comments that improved the manuscript. 
Review statement. This paper was edited by Stephen Howell and reviewed by two anonymous referees.

\section{References}

Abdalati, W., Zwally, H. J., Bindschadler, R., Csatho, B., Farrell, S. L., Fricker, H. A., Harding, D., Kwok, R., Lefsky, M., Markus, T., Marshak, A., Neumann, T., Palm, S., Schutz, B., Smith, B., Spinhirne, J., and Webb, C.: The ICESat-2 Laser Altimetry Mission, P. IEEE, 98, 735-751, https://doi.org/10.1109/JPROC.2009.2034765, 2010.

Berglund, R. and Eriksson, P. B.: National ice service operations and products around the world, chap. 5.2, in: Cold Regions Science and Marine Technology, edited by: Shen, H., Encyclopedia of Life Support Systems, 2015.

BIM: Baltic Sea Icebreaking Report 2018-2019, Tech. rep., Baltic Icebreaking Management (BIM), available at: http:// baltice.org/app/static/pdf/BIMFinalReport2019.pdf (last access: 1 April 2020), 2019.

Brown, M. E., Arias, S. D., Neumann, T., Jasinksi, M. F., Posey, P., Babonis, G., Glenn, N. F., Birkett, C. M., Escobar, V. M., and Markus, T.: Applications for ICESat2 Data, IEEE Geosci. Remote Sens. Magazine, 24-37, https://doi.org/10.1109/MGRS.2016.2560759, 2016.

Brunt, K. M., Neumann, T. A., and Smith, B. E.: Assessment of ICESat-2 Ice Sheet Surface Heights, Based on Comparisons Over the Interior of the Antarctic Ice Sheet, Geophys. Res. Lett., 46, 13072-13078, https://doi.org/10.1029/2019GL084886, 2019.

Duncan, K., Farrell, S. L., Connor, L. N., Richter-Menge, J., Hutchings, J. K., and Dominguez, R.: High-resolution airborne observations of sea-ice pressure ridge sail height, Ann. Glaciol., 59, 137-147, https://doi.org/10.1017/aog.2018.2, 2018.

Farrell, S., Duncan, K., Buckley, E., Richter-Menge, J., and Li, R.: Mapping Sea Ice Surface Topography in High Fidelity with ICESat-2, Geophy. Res. Lett., 47, e2020GL090708, https://doi.org/10.1029/2020GL090708, 2020.

Farrell, S. L., Brunt, K. M., Ruth, J. M., Kuhn, J. M., Connor, L. N., and Walsh, K. M.: Sea-ice freeboard retrieval using digital photon counting laser altimetry, Ann. Glaciol., 56, 167-174, https://doi.org/10.3189/2015AoG69A686, 2015.

Fredensborg Hansen, R. M.: reneefredensborg/DIR-from-IS2: Estimating elevation anomalies (ridge sails) and degree of ice ridging (DIR) from ICESat-2 (IS2) (Version v1.1), Zenodo, https://doi.org/10.5281/zenodo.4636435, 2021.

Gegiuc, A., Similä, M., Karvonen, J., Lensu, M., Mäkynen, M., and Vainio, J.: Estimation of degree of sea ice ridging based on dual-polarized C-band SAR data, The Cryosphere, 12, 343-364, https://doi.org/10.5194/tc-12-343-2018, 2018.

Goerlandt, F., Goite, H., Banda, O. A. V., Höglund, A., AhonenRainio, P., and Lensu, M.: An analysis of wintertime navigational accidents in the Northern Baltic Sea, Safety Science, 92, 66-84, https://doi.org/10.1016/j.ssci.2016.09.011, 2017.

HELCOM: HELCOM Map And Data Service, available at: http: //maps.helcom.fi/website/mapservice/ (last access: 21 October 2020), 2021.
Horvat, C., Blanchard-Wrigglesworth, E., and Petty, A.: Observing Waves in Sea Ice With ICESat-2, Geophys. Res. Lett., 47, e2020GL087629, https://doi.org/10.1029/2020GL087629, 2020.

IMO: International code for ships operating in polar waters (Polar Code), Tech. rep., Internatinal Maritime Organisation (IMO), Marine Environment Protection Committee (MEPC), available at: http://www.imo.org/en/MediaCentre/HotTopics/polar/ Documents/POLARCODETEXTASADOPTED.pdf, last access: 17 August 2020.

Karvonen, J.: Operational SAR-based sea ice drift monitoring over the Baltic Sea, Ocean Sci., 8, 473-483, https://doi.org/10.5194/os-8-473-2012, 2012.

Karvonen, J., Heiler, I., Seniä, A., and Hackett, B.: Product User Manual: For Baltic Sea - Sea Ice Observations SEAICE_BAL_SEAICE_L4_NRT_OBSERVATIONS_011_004/011, copernicus Marine Service, available at: https: //resources.marine.copernicus.eu/documents/PUM/ CMEMS-SI-PUM-011-004-011.pdf (last access: 12 March 2021), 2020.

Klotz, B. W., Neuenschwander, A., and Magruder, L. A.: HighResolution Ocean Wave and Wind Characteristics Determined by the ICESat-2 Land Surface Algorithm, Geophys. Res. Lett., 47, e2019GL085907, https://doi.org/10.1029/2019GL085907, 2020.

Kovacs, A., Weeks, W., Ackley, S., and Hibler, W.: Structure of a Multi-Year Pressure Ridge, Arctic, 26, 22-31, https://doi.org/10.14430/arctic2893, 1973.

Kwok, R., Kacimi, S., Markus, T., Kurtz, N. T., Studinger, M., Sonntag, J. G., Manizade, S. S., Boisvert, L. N., and Harbeck, J. P.: ICESat-2 Surface Height and Sea Ice Freeboard Assessed with ATM Lidar Acquisitions From Operation IceBridge, Geophys. Res. Lett., 46, 11228-11236, https://doi.org/10.1029/2019GL084976, 2019a.

Kwok, R., Markus, T., Kurtz, N. T., Neumann, T. A., Farrell, S. L., Cunningham, C. F., Hancock, D. W., Ivanoff, A., and Wimert, J. T.: Surface Height and Sea Ice Freeboard of the Arctic Ocean from ICESat-2: Characteristics and Early Results, J. Geophys. Res.-Oceans, 124, 6942-6959, https://doi.org/10.1029/2019JC015486, 2019b.

Kwok, R., Petty, A. A., Bagnardi, M., Kurtz, N. T., Cunningham, G. F., Ivanoff, A., and Kacimi, S.: Refining the sea surface identification approach for determining freeboards in the ICESat-2 sea ice products, The Cryosphere, 15, 821-833, https://doi.org/10.5194/tc-15-821-2021, 2021.

Lewis, J., Leppäranta, M., and Granberg, H.: Statistical properties of sea ice surface topography in the Baltic Sea, Tellus A, 45, 127-142, 1993.

Leys, C., Ley, C., Klein, O., Bernard, P., and Licata, L.: Detecting outliers: Do not use standard deviation around the mean, use absolute deviation around the median, J. Exp. Soc. Psychol., 49, 764-766, https://doi.org/10.1016/j.jesp.2013.03.013, 2013.

Manninen, A.: Multiscale Surface Roughness and Backscattering, Prog. Electromagn. Res., 16, 175-203, https://doi.org/10.2528/PIER96060700, 1997.

Markus, T., Neumann, T., Martino, A., Abdalati, W., Brunt, K., Csatho, B., Farrell, S., Fricker, H., Gardner, A., Harding, D., Jasinksi, M., Kwok, R., Magruder, L., Lubin, D., Lutchke, S., Morison, J., Nelson, R., Neuenschwander, A., Palm, S., Popescu, S., Schum, C., Schutz, B. E., Smith, B., Yang, Y., and Zwally, J.: The Ice, Cloud and land El- 
evation Satellite-2 (ICESat-2): Science requirements, concept and implementation, Remote Sens. Environ., 190, 260-273, https://doi.org/10.1016/j.rse.2016.12.029, 2017.

Melia, N., Haines, K., and Hawkins, E.: Sea ice decline and 21st century trans-Arctic shipping routes, Geophys. Res. Lett., 43, 9720-9728, https://doi.org/10.1002/2016GL069315, 2016.

NASA EarthData: ASF Data Search, available at: https://search.asf. alaska.edu/\#/, last access: 18 February 2021.

Neumann, T., Brenner, A., Hancock, D., Lutchke, S., Lee, J., Robbins, J., Harbeck, K., Saba, J., Brunt, K., Gibbons, A., Saba, J., Brunt, K., and ICESat-2 Science Team: ATLAS/ICESat2 L2A Global Geolocated Photon Data, Version 2, NSIDC, National Snow and Ice Data Center Boulder, CO, USA, https://doi.org/10.5067/ATLAS/ATL03.002, 2019a.

Neumann, T., Martino, A. J., Markus, T., Bae, S., Bock, M. R., Brenner, A. C., Brunt, K. M., Cavanaugh, J., Fernandes, S. T., Hancock, D. W., Harbeck, K., Lee, J., Kurtz, N. T., Luers, P. J., Lutchke, S. B., Magruder, L., Pennington, T. A., RamosIzquierdo, L., Rebold, T., Skoog, J., and Thomas, T. C.: The Ice, Cloud and Land Elevation Satellite - 2 mission: A global geolocated photon product derived from the Advanced Topographic Laser Altimeter System, Remote Sens. Environ., 233, 111325, https://doi.org/10.1016/j.rse.2019.111325, 2019b.

Neumann, T., Brenner, A., Hancock, D., Robbins, J., Saba, J., Harbeck, K., Gibbons, A., Lee, J., Lutchke, S., and Rebold, T.: Algorithm Theoretical Basis Document (ATBD) for Global Geolocated Photons (ATL03), Goddard Space Flight Center, Release 003, Tech. rep., https://doi.org/10.5067/ESL18THQ8RNT, 2020.
Petty, A. A., Bagnardi, M., Kurtz, N. T., Tilling, R., Fons, S., Armitage, T., Horvat, C., and Kwok, R.: Assessment of ICESat-2 Sea Ice Surface Classification with Sentinel-2 Imagery: Implications for Freeboard and New Estimates of Lead and Floe Geometry, Earth Space Sci., 8, e2020EA001491, https://doi.org/10.1029/2020EA001491, 2021.

Ronkainen, I., Lehtiranta, J., Lensu, M., Rinne, E., Haapala, J., and Haas, C.: Interannual sea ice thickness variability in the Bay of Bothnia, The Cryosphere, 12, 3459-3476, https://doi.org/10.5194/tc-12-3459-2018, 2018.

Schweiger, A. J.: Changes in seasonal cloud cover over the Arctic seas from satellite and surface observations, Geophys. Res. Lett., 31, L12207, https://doi.org/10.1029/2004GL020067, 2004.

Stasolla, K. and Neyt, X.: An Operation Tool for the Automatic Detection and Removal of Border Noise in Sentinel-1 GRD Products, Sensors, 18, 3454, https://doi.org/10.3390/s18103454, 2018.

Tilling, R., Kurtz, N. T., Bagnardi, M., Petty, A. A., and Kwok, R.: Detection of Melt Ponds on Arctic Summer Sea Ice From ICESat-2, Geophys. Res. Lett., 47, e2020GL090644, https://doi.org/10.1029/2020GL090644, 2020.

WMO: Sea-Ice Information Services in the World, vol. 574, 2010 edn., World Meteorological Organisation (WMO), 2010. 